\title{
On Thermodynamic Stability of Hydrogenated Graphene Layers, Rele- vance to the Hydrogen on-board Storage
}

\author{
Yury S. Nechaev ${ }^{1, *}$ and T. Nejat Veziroglu ${ }^{2}$ \\ ${ }^{1}$ Bardin Institute for Ferrous Metallurgy, Kurdjumov Institute of Metals Science and Physics, Vtoraya Baumanskaya St., \\ 9/23, Moscow 105005, Russia \\ ${ }^{2}$ International Association for Hydrogen Energy, 5794 SW 40 St. \#303, Miami, FL 33155, USA
}

\begin{abstract}
The present analytical study using thermodynamic methods for analysis of data from a number of theoretical and experimental works, devoted to the current problem of thermodynamic stability and related thermodynamic characteristics of the following graphene layers systems: 1) double-side hydrogenated graphene of composition $\mathrm{CH}$ - theoretical graphane (Sofo et al. 2007) and experimental graphane (Elias et al. 2009); 2) theoretical single-side hydrogenated graphene of composition $\mathrm{CH} ; 3$ ) theoretical single-side hydrogenated graphene of composition $\mathrm{C}_{2} \mathrm{H}$ - graphone; 4) experimental hydrogenated epitaxial graphene, bilayer graphene and a few layers of graphene on $\mathrm{SiO}_{2}$ or other substrates; 5) experimental and theoretical single-external side hydrogenated single-walled carbon nanotubes, and experimental hydrofullerene $\mathrm{C}_{60} \mathrm{H}_{36} ; 6$ ) experimental single-internal side hydrogenated (up to $\mathrm{C}_{2} \mathrm{H}$ or $\mathrm{CH}$ composition) graphene nanoblisters with intercalated high pressure $\mathrm{H}_{2}$ gas inside them, formed on a surface of highly oriented pyrolytic graphite or epitaxial graphene under the atomic hydrogen treatment; and 7) experimental hydrogenated graphite (multigraphene) nanofibers with intercalated solid $\mathrm{H}_{2}$ nano-regions inside them. The main target of the present study is to show a possible breakthrough in solving the problem of hydrogen on-board storage in fuel cell powered vehicles (Nechaev 2011-2012).
\end{abstract}

Keywords: Hydrogenated graphene layers, graphanes, thermodynamic stability, solid hydrogen intercalated into hydrogenated graphite nanofibers, the hydrogen on-board storage in fuel-cell-powered vehicles

\section{INTRODUCTION}

As noted in a number of articles 2007 through 2013, hydrogenation of graphene - a single layer of carbon atoms arranged in a honeycomb lattice $[1,2]$, as a prototype of covalent chemical functionalization and an effective tool to open the band gap of grapheme, is of fundamental importance.

It is relevant to the current problem of hydrogen on-board storage, and also to the related problems of thermodynamic stability and thermodynamic characteristics of the following systems:

1). double-side hydrogenated graphene - theoretical graphane of composition $\mathrm{CH}[3,4]$ and experimental graphane [5];

2). theoretical single-side hydrogenated graphene of composition $\mathrm{CH}$ (SSHG) [6-8];

3). theoretical single-side hydrogenated graphene of composition $\mathrm{C}_{2} \mathrm{H}$ (graphone) [9];

4). experimental hydrogenated epitaxial graphene, bigraphene and a few layer graphene on $\mathrm{SiO}_{2}$ or other substrates [5];

*Address correspondence to these authors at the International Association for Hydrogen Energy, 5794 SW 40 St. \#303, Miami, FL 33155, USA;

Tel: +7495 491-02-62; Fax:+7495 777-93-50; E-mail: yuri1939@inbox.ru
5). experimental and theoretical single-external-side hydrogenated single-walled carbon nanotubes (SWCNTs) of composition about $\mathrm{C}_{2} \mathrm{H}$ and experimental hydrofullerene $\mathrm{C}_{60} \mathrm{H}_{36}$ [10-14];

6). experimental single-internal-side hydrogenated graphene nanoblisters possessing of a very high Young's modulus (with intercalated into them $\mathrm{H}_{2}$ gas of a high pressure) formed on the surface of highly oriented pyrolytic graphite (HOPG) or epitaxial graphene under the definite atomic hydrogen treatment ([15-21]);

7). experimental hydrogenated graphite nanofibers possessing of a high Young's modulus (with intercalated into them solid $\mathrm{H}_{2}$ ) that is relevante to the problem of the hydrogen on-board storage [18-21].

In this analytical review, results of thermodynamic analysis and comparison of some theoretical and experimental data are presented, including those from the most cited works $[3,5]$ and from the least non-cited works [18-21].

In [8], the double-side hydrogenation of graphene is now well understood, at least from a theoretical point of view. For example, Sofo et al. predicted theoretically a new insulating material of $\mathrm{CH}$ composition called graphane - double-side hydrogenated graphene, in which each hydrogen atom adsorbs on top of a carbon atom from both sides, so that the hydrogen atoms adsorbed in different carbon sublattices are on different sides of the monolayer plane [3]. The formation 
of graphane was attributed to the efficient strain relaxation for $s p^{3}$ hybridization, accompanying with a strong (diamondlike) distortion of the graphene network [3, 22]. In contrast to graphene - a zero-gap semiconductor, graphane is an insulator with an energy gap of $E_{\mathrm{g}} \approx 5.4 \mathrm{eV}[4,23]$. Only if hydrogen atoms adsorbed on one side of graphene (in graphane) are retained, we obtain graphone of $\mathrm{C}_{2} \mathrm{H}$ composition, which is a magnetic semiconductor with $E_{\mathrm{g}} \approx 0.5 \mathrm{eV}$ and a Curie temperature of $T_{\mathrm{c}} \approx 300-400 \mathrm{~K}$ [24].

As was noted in [6], neither graphone nor graphane are suitable for real practical applications, since the former has a low value of $E_{\mathrm{g}}$, and undergoes a rapid disordering because of hydrogen migration to neighboring vacant sites even at a low temperature, and the latter cannot be prepared on a solid substrate [9].

Single-side hydrogenated graphene (SSHG) of $\mathrm{CH}$ composition $[7,25]$ is an alternative to graphane, in which hydrogen atoms are adsorbed only one side. In contrast to graphone, they are adsorbed on all carbon atoms rather than on every second carbon atom. The value of $E_{\mathrm{g}}$ in SSHG is sufficiently high (1.6 eV lower than in graphane), and it can be prepared on a solid substrate in principle. But, this quasitwo-dimensional carbon-hydrogen theoretical system is shown to have a relatively low thermal stability, which makes it difficult to use SSGG in practice $[6,7]$.

As seen in [7], it may be inappropriate to call the covalently bonded SSHG system $s p^{3}$ hybridized, since the characteristic bond angle of $109.5^{\circ}$ is not present anywhere, i.e., there is no diamond-like strong distortion of the graphene network, rather than in graphane. Generally in the case of a few hydrogen atoms interacting with graphene or even for graphane, the underlining carbon atoms are displaced from their locations. For instance, there may be the diamond-like local distortion of the graphene network, showing the signature of $s p^{3}$ bonded system. However, in SSHGraphene all the carbon atoms remain in one plane, making it difficult to call it $s p^{3}$ hybridized. Obviously, this is some specific $s p^{3}$-like hybridization. Such model is taken into further consideration in this analytical study [10-21].

In a number of works, it shows that hydrogen chemisorption corrugates the graphene sheet in fullerene, carbon nanotubes, graphite and graphene, and transforms it from a semimetal into a semiconductor [3, 5, 25-28]. This can even induce magnetic moments [29-31].

It is worth repeating [8] the prediction for the double-side hydrogenated graphene [3] was partially confirmed by Elias et al. [5]. They demonstrated that graphene can react with atomic hydrogen, which transforms this highly conductive zero-overlap semimetal into an insulator of high thermal stability, and the double-side hydrogenation of graphene is reversible. The authors themselves expressed some doubts, relevant to the complete adequacy of the experimental graphane to the theoretical one [3]. Alternatively, they supposed, that the experimental graphane (a free-standing membrane) produced by them, may have a more complex hydrogen bonding than the one suggested by the theory, and that the latter may be as an "until now theoretical material".

In the case of epitaxial graphene on substrates such as $\mathrm{SiO}_{2}$ and others, hydrogenation occurs only on the top basal plane of graphene, and it is not accompanied with a strong (diamond-like) distortion of the graphene network, but only with some ripples. The first experimental indication of such a specific single-side hydrogenation came from Elias et al. [5]. The authors mentioned a possible contradiction with the theoretical results of Sofo et al. [3], which had down-played the possibility of a single side hydrogenation. They proposed an important facilitating role of the material ripples for hydrogenation of graphene on $\mathrm{SiO}_{2}$, and believed that such a single-side hydrogenated epitaxial graphene can be a disordered material, similar to graphene oxide, rather than a new graphene-based crystal - the experimental graphane produced by them.

On the other hand, it is expedient to note that changes in Raman spectra of graphene caused by hydrogenation were rather similar (with respect to locations of $D, G, D^{\prime}, 2 D$ and $\left(\mathrm{D}+\mathrm{D}^{\prime}\right)$ peaks) both for the epitaxial graphene on $\mathrm{SiO}_{2}$ and for the free-standing graphene membrane [5].

As it is supposed by many scientists $[5,8]$, such a single side hydrogenation of epitaxial graphene occurs, because the diffusion of hydrogen along the graphene- $\mathrm{SiO}_{2}$ interface is negligible, and perfect graphene is impermeable to any atom and molecule [32]. But these two aspects are of the kinetic character, and therefore they can not influence the thermodynamic predictions $[3,24,31]$.

Authors of [8] noted that their test calculations show that the barrier for the penetration of a hydrogen atom through the six-membered ring of graphene is larger than $2.0 \mathrm{eV}$. Thus, they believe that it is almost impossible for a hydrogen atom to pass through the six-membered ring of graphene at room temperature (from a private communication with H.G. Xiang and M.-H. Whangbo).

In the present analytical review, a real possibility is considered when a hydrogen atom can pass through the graphene network at room temperature. This is the case of existening relevant defects in graphene, i.e., in grain boundaries and/or vacancies [33-42]. This is related to further consideration of data in this analytical study as mentioned above.

Previous theoretical studies suggest that single-side hydrogenation of ideal graphene would be thermodynamically unstable $[31,24]$. Thus [8], it remains a puzzle why the single-side hydrogenation of epitaxial graphene is possible and even reversible, and why the hydrogenated species are stable at room temperatures $[5,43]$. This puzzling situation is also considered in the present analytical review. The main aim of this study is to show a real possibility, at least, from the thermodynamic point of view, of the existence of hydrogenated graphene-based nanostructures [18-21] possessing very high Young's modulus, and also showing a real possibility of intercalation in such nanostructures of solid molecular hydrogen under definite hydrogenation conditions relevant to the current problem of hydrogen on-board storage in fuelcell-powered vehicles.

\section{ANALYSIS AND COMPARISON OF DATA ON THEORETICAL AND EXPERIMENTAL GRAP- HANES}

\subsection{Consideration of Data on Theoretical Graphanes (CH)}

In work [3], the stability of graphane with formula $\mathrm{CH}$, a fully saturated extended two-dimentional hydrocarbon de- 
rived from a single graphene sheet, has been predicted on the basis of the first principles total-energy calculations. All of the carbon atoms are in $s p^{3}$ hybridization forming a hexagonal network (a strongly diamond-like distorted graphene network) and the hydrogen atoms are bonded to carbon on both sides of the plane in an alternative manner. It has been found [3] that graphane can have two favorable conformations: a chair-like (diamond-like) conformer and a boat-like (zigzag-like) conformer.

The diamond-like conformer [3] is more stable than the zigzag-like one. This was concluded from the results of the calculations of binding energy ( $\left.\Delta H_{\text {bind.(graphane) }}\right)$ (i.e., the difference between the total energy of the isolated atoms and the total energy of the compounds), and the standard energy of formation $\left(\Delta H_{\mathrm{f} 298 \text { (graphane) }}^{0}\right)$ of the compounds $\left(\mathrm{CH}_{\text {(graphane) }}\right)$ from crystalline graphite $\left(\mathrm{C}_{\text {(graphite) }}\right)$ and gaseous molecular hydrogen $\left(\mathrm{H}_{2(\mathrm{gas})}\right)$ at the standard pressure and temperature conditions [3].

For the diamond-like graphane, the former quantity is $\Delta H_{\text {bind.(graphane) }}=6.56 \mathrm{eV} / \mathrm{atom}$, and the latter one is $\Delta H_{1}=$ $\Delta H_{\mathrm{f} 298(\text { graphane) }}=-0.15 \mathrm{eV} / \mathrm{atom}$. The latter quantity corresponds to the following reaction:

$\mathrm{C}_{\text {(graphite) }}+1 / 2 \mathrm{H}_{2(\text { gas })} \rightarrow \mathrm{CH}_{\text {(graphane) }}\left(\Delta H_{1}\right)$

where $\Delta H_{1}$ is the standard energy (enthalpy) change for this reaction.

By using the theoretical quantity [3] of $\Delta H_{\text {f298(graphane), }}^{0}$ one can evaluate, within the framework of the thermodynamic method of cyclic processes [44], a value of the energy of formation $\left(\mathrm{\Delta H}_{2}\right)$ of graphane $\left(\mathrm{CH}_{\text {(graphane) }}\right)$ from graphene $\left(\mathrm{C}_{\text {(graphene) }}\right)$ and gaseous atomic hydrogen $\left(\mathrm{H}_{\text {(gas) }}\right)$. For this, it is necessary to take into consideration the following three additional reactions:

$\mathrm{C}_{\text {(graphene) }}+\mathrm{H}_{\text {(gas) }} \rightarrow \mathrm{CH}_{\text {(graphane) }}$
$\mathrm{C}_{\text {(graphene) }} \rightarrow \mathrm{C}_{\text {(graphite) }} \quad\left(\Delta H_{3}\right)$
$\mathrm{H}_{\text {(gas) }} \rightarrow 1 / 2 \mathrm{H}_{2 \text { (gas) }} \quad\left(H_{4}\right)$

where $\Delta H_{2}, \Delta H_{3}$ and $\Delta H_{4}$ are the standard energy (enthalpy) changes.

Reaction (2) can be presented as a sum of reactions (1), (3) and (4) using the framework of the thermodynamic method of cyclic processes [44]:

$\Delta H_{2}=\left(\Delta H_{3}+\Delta H_{4}+\Delta H_{1}\right)$

Substituting in Eq. (5) the known experimental values of $\Delta H_{4}=-2.26 \mathrm{eV} /$ atom and $\Delta H_{3} \approx-0.05 \mathrm{eV} /$ atom $[25,45]$, and also the theoretical value [3] of $\Delta H_{1}=-0.15$ эB/atom, one can obtain a desired value of $\Delta H_{2}=-2.5 \pm 0.1 \mathrm{eV} /$ atom. The quantity of $-\mathrm{SH}_{2}$ characterizes the break-down energy of C$\mathrm{H} s p^{3}$ bond in graphane (Fig. 1), relevant to the breaking away of one hydrogen atom from the material, which is $\Delta H_{\text {(C-H)graphane }}=-\Delta H_{2}=2.5 \pm 0.1 \mathrm{eV}$.

In evaluating the above mentioned value of $\Delta H_{3}$, one can use the experimental data [45] on the graphite sublimation energy at $298 \mathrm{~K}\left(\Delta H_{\text {subl.(graphite) }}=7.41 \pm 0.05 \mathrm{eV} /\right.$ atom $)$, and the theoretical data [25] on the binding cohesive energy at about $0 \mathrm{~K}$ for graphene $\left(\Delta H_{\text {cohes.(graphene) }}=7.40 \mathrm{eV} /\right.$ atom $)$. Therefore, neglecting the temperature dependence of these quantities in the interval of $0-298 \mathrm{~K}$, and one obtains the value of $\Delta H_{3} \approx-0.05 \mathrm{eV} /$ atom.

$\Delta H_{\text {cohes.(graphene) }}$ quantity characterizes the break-down energy of $1.5 \mathrm{C}-\mathrm{C} s p^{2}$ bond in graphene, relevant to the breaking away of one carbon atom from the material. Consequently, one can evaluate the break-down energy of C-C $s p^{2}$ bonds in graphene, which is $\Delta H_{\text {(C-C)graphene }}=4.93 \mathrm{eV}$. This theoretical quantity coincides with the similar empirical quantities obtained in [18-21] from the graphite sublimation energy $\Delta H_{\text {subl.(graphite) }}$ for C-C $s p^{2}$ bonds in graphene and graphite, which are $\Delta H_{(\mathrm{C}-\mathrm{C}) \text { graphene }} \approx \Delta H_{\text {(C-C) graphite }}=4.94 \pm$ $0.03 \mathrm{eV}$. The similar empirical quantity for C-C $s p^{3}$ bonds in diamond obtained from the diamond sublimation energy $\Delta H_{\text {subl.(diamond) }}$ is $\Delta H_{\text {(C-C)diamond }}=3.69 \pm 0.02 \mathrm{eV}$ [18-21].

It is important to note that in [25] chemisorption of hydrogen on graphene was studied using atomistic simulations, with a second generation reactive empirical bond order of Brenner inter-atomic potential. As it has been shown, the cohesive energy of graphane $(\mathrm{CH})$ in the ground state is $\Delta H_{\text {cohes.(graphane) }}=5.03 \mathrm{eV} /$ atom $(\mathrm{C})$. This results in the binding of hydrogen energy, which is $\Delta H_{(\mathrm{C}-\mathrm{H}) \text { graphane }}=1.50$ eV/atom(H) [25].

The theoretical $\Delta H_{\text {bind.(graphane) }}$ quantity [3] characterizes the break-down energy of one $\mathrm{C}-\mathrm{H} s p^{3}$ bond and $1.5 \mathrm{C}-\mathrm{C} s p^{3}$ bonds (Fig. 1). Hence, by using the above mentioned values [3] of $\Delta H_{\text {bind.(graphane) }}$ and $\Delta H_{(\mathrm{C}-\mathrm{H}) \text { graphane }}$, one can evaluate the break-down energy of C-C $s p^{3}$ bonds in the theoretical graphane [3], which is $\Delta H_{(\mathrm{C}-\mathrm{C}) \text { graphane }}=2.7 \mathrm{eV}$. Also, by using the above noted theoretical values [25] of $\Delta H_{\text {coh }} \mathrm{e}_{\text {s.(graphane) }}$ and $\Delta H_{\text {(C-H)graphane, one can evaluate similarly the break-down }}$ energy of C-C $s p^{3}$ bonds in the theoretical graphane [25], which is $\Delta H_{(\mathrm{C}-\mathrm{C}) \text { graphane }}=2.35 \mathrm{eV}$. Comparing the obtained values of $\Delta H_{\text {(C-C)graphane, }} \Delta H_{\text {(C-C)graphene, }}, \Delta H_{\text {(C-C)graphite }}$ and $\Delta H_{\text {(C- }}$ C)diamond show that the elastic and intrinsic strength properties depending on $\Delta H_{(\mathrm{C}-\mathrm{C})}$ equantities, and especially, the Young's modulus of the theoretical graphanes $[3,25]$ can be much less than those for perfect graphene $[1,25]$, perfect graphite [45] or perfect diamond [45] possessing of the lower $\Delta H_{(\mathrm{C}-\mathrm{C})}$ values.

\subsection{Consideration of Data on Hydrogen Thermal De- sorption from Theoretical and Experimental Graphanes}

In [4], the process of hydrogen thermal desorption from graphane [3] has been studied using the method of molecular dynamics. The temperature dependence for $T=1300-3000 \mathrm{~K}$ at the time $\left(\tau_{0.01}\right)$ of hydrogen desorption onset (i.e., the time of removal $\sim 1 \%(-\Delta C)$ of the initial hydrogen concentration $C_{0} \approx 0.5$ (in atomic fractions), $-\Delta C / C_{0} \approx 0.01$ ) from the $\mathrm{C}_{54} \mathrm{H}_{(54+18)}$ clusteres (with 18 hydrogen passivating atoms at the edges to saturate the dangling bonds of $s p^{3}$-hybridized carbon atoms) have been calculated. The corresponding activation energy of $E_{\mathrm{a}}=2.46 \pm 0.17 \mathrm{eV}$ and the corresponding near temperature independent frequency factor $\mathrm{A}=(2.1 \pm$ $0.5) \cdot 10^{17} \mathrm{~s}^{-1}$ have also been calculated. The process of hydrogen desorption at $T=1300-3000 \mathrm{~K}$ has been described in terms of the following standard Arrhenius relationship:

$1 / \tau_{0.01}=A \exp \left(-E_{\mathrm{a}} / k_{\mathrm{B}} T\right)$ 
where $k_{\mathrm{B}}$ is the Boltzmann constant. The authors predicted that their results would not contradict the experimental data [5], according to which the nearly complete desorption of hydrogen $\left(-\Delta C / C_{0} \approx 0.9\right)$ from a graphane membrane was achieved by annealing it in argon at $T=723 \mathrm{~K}$ for 24 hours (i.e., $\tau_{0.9(\text { membr.) }) 723 \mathrm{~K}}=8.64 \cdot 10^{4} \mathrm{~s}$ ).

By using Eq. (6), the authors evaluated the quantity of $\tau_{0.01 \text { (graphane) }}$ for $T=300 \mathrm{~K}\left(\sim 1 \cdot 10^{24} \mathrm{~s}\right)$ and for $T=600 \mathrm{~K}$ $\left(\sim 2 \cdot 10^{3} \mathrm{~s}\right)$. However, they note that the above two values of $\tau_{0.01(\text { graphane) }}$ should be considered as rough estimates. Using Eq. (6), one can evaluate the value of $\tau_{0.01 \text { (graphane) } 723 \mathrm{~K}} \approx 0.7 \mathrm{~s}$ for $T=723 \mathrm{~K}$, which is much less (by five orders) than the

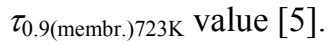

In the framework of the formal kinetics approximation of the first order rate reaction [46], a characteristic quantity for the reaction of hydrogen desorption is $\tau_{0.63}$ - the time of the removal of $\sim 63 \%(-\Delta C)$ of the initial hydrogen concentration $C_{0}$ (i.e., $-\Delta C / C_{0} \approx 0.63$ ) from the hydrogenated graphene. Such a first order rate reaction (desorption) can be described by the following equations $[14,46]$ :

$d C / d t=-K C$

$\left(C / C_{0}\right)=\exp (-K t)=\exp \left(-t / \tau_{0.63}\right)$

$K=\left(1 / \tau_{0.63}\right)=K_{0} \exp \left(-\Delta H_{\text {des. }} / k_{\mathrm{B}} T\right)$

where $K=\left(1 / \tau_{0.63}\right)$ is the reaction (desorption) rate constant, $\Delta H_{\text {des. }}$ is the reaction (desorption) activation energy, and $K_{0}$ is the per-exponential (or frequency) factor of the reaction rate constant. In the case of a non-diffusion rate limiting kinetics, the quantity of $K_{0}$ may be the corresponding vibrational frequency $\left(K_{0}=v\right)$, and Eq. (9) may be related to the Polanyi-Wigner equation [14]. By substituting in Eq. (8) the quantities [4] of $t=\tau_{0.01(\text { graphane) } 723 \mathrm{~K}}$ and $\left(C / C_{0}\right)=0.99$, one can evaluate the desired quantity $\tau_{0.63 \text { (graphane) } 723 \mathrm{~K}} \approx 70 \mathrm{~s}$. Hence, using Eq. (9) results in the analytical quantity of $A_{a n}$. $=2 \cdot 10^{15} \mathrm{~s}^{-1}$ corresponding to data [4].

Analogically, one can evaluate the desired quantity $\tau_{0.63(\text { membr. }) 723 \mathrm{~K}}=\left(1 / K_{(\mathrm{membr} .) 723 \mathrm{~K}}\right) \approx 3.8 \cdot 10^{4} \mathrm{~s}$ corresponding to

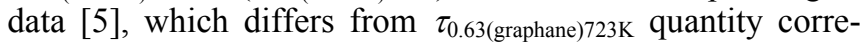
sponding to data [4] by about three orders. By substituting in Eq. (9) the quantity of $K=K_{\text {(membr.)723K }}$ and supposing that $\Delta H_{\text {des. }}=\Delta H_{\text {des.(membr.) }} \approx \Delta H_{\text {C-H(graphane })}=-\Delta H_{2}$, where $\Delta H_{\text {des.(membr.) }}$ corresponds to the desorption activation energy in [5], one can evaluate the quantity $K_{0 \text { (membr.) }}=v_{\text {(membr.) }} \approx$ $7 \cdot 10^{12} \mathrm{~s}^{-1}$ for the experimental graphane membranes [5]. The obtained quantity of $v_{\text {(membr.) }}$ is less by one and a half orders of the vibrational frequency $\nu_{\mathrm{RD}}=2.5 \cdot 10^{14} \mathrm{~s}^{-1}$ corresponding to the D Raman peak $\left(1342 \mathrm{~cm}^{-1}\right)$ for hydrogenated graphene membrane and epitaxial graphene on $\mathrm{SiO}_{2}$. The activation of this peak in the hydrogenated samples authors [5] attribute to breaking of the translation symmetry of C-C $s p^{2}$ bonds after formation of $\mathrm{C}-\mathrm{H} s p^{3}$ bonds. Also, $v_{\text {(membr.) }}$ is less by one order of the vibrational frequency $v_{\text {HREELS }}=8.7 \cdot 10^{13} \mathrm{~s}^{-1}$ corresponding to an additional HREELS peak in [47] arising from $\mathrm{C}-\mathrm{H} s p^{3}$ stretching appears at $369 \mathrm{meV}$ after a partial hydrogenation of the epitaxial graphene. The authors [47] suppose that this peak can be assigned to the vertical $\mathrm{C}-\mathrm{H}$ bonding, giving direct evidence for hydrogen attachment on the epitaxial graphene surface.
Taking into account $\nu_{\mathrm{RD}}$ and $\nu_{\mathrm{HREELS}}$ quantities [5, 47], and substituting in Eq. (9) quantities of $K=K_{\text {(membr.) } 723 \mathrm{~K}}=$ $1 / \tau_{0.63 \text { (membr.)723K }}$ and $K_{0} \approx K_{0 \text { (membr.) }} \approx v_{\text {HREELS }}$, one can evaluate $\Delta H_{\text {des.(membr. })}=\Delta H_{\mathrm{C}-\mathrm{H} \text { (membr.) }} \approx 2.66 \mathrm{eV}$. In such approximation, the obtained value of $\Delta H_{\mathrm{C}-\mathrm{H}(\mathrm{membr})}$ coincides (within the errors) with the experimental value [13] of the breakdown energy of $\mathrm{C}-\mathrm{H} s p^{3}$-like bonds in hydrofullerene $\mathrm{C}_{60} \mathrm{H}_{36}$ $\left(\Delta H_{\mathrm{C}-\mathrm{H}(\mathrm{C} 60 \mathrm{H} 36)}=2.64 \pm 0.01 \mathrm{eV}\right)[5]$.

The above analysis of the related data shows that for the experimental [5] graphene membranes (hydrogenated up to the near-saturation) can be used the following thermodesorption characteristics, relevant to Eq. (9), of the empirical character: $\Delta H_{\text {des.(membr.) }}=\Delta H_{\text {C-H(membr.) }}=2.6 \pm 0.1 \mathrm{eV}, K_{0 \text { (membr.) }}=$ $v_{\mathrm{C}-\mathrm{H} \text { (membr.) }} \approx 5 \cdot 10^{13} \mathrm{~s}^{-1}$. The analysis also shows that this is a case for a non-diffusion rate limiting kinetics, when Eq. (9) corresponds to the Polanyi-Wigner one [14]. Certainly, these tentative analytical results for the experimental [5] graphene membranes could be unambiguosly confirmed and/or modified by receiving and treating within Eqs. $(8,9)$ of the experimental data (similar to [5]) on $\tau_{0.63}$ at several annealing temperatures.

The above noted fact that the empirical quantity $\tau_{0.63 \text { (membr.723K) }}$ is much larger (by about 3 orders), than the theoretical one $\left(\tau_{0.63(\text { graphane } 723 \mathrm{~K})}\right)$ corresponding to data [4] is consistent with that mentioned in [5]. It was noted the alternative possibility that the experimental graphane membrane (a free-standing membrane) might have a more complex hydrogen bonding, than the suggested by the theory [3]. This may point out for further theoretical and experimental developments.

\subsection{Consideration of Thermodynamic Probability Exis- tence of Hydrogenated Graphenes - Graphanes* Possess- ing of Very High Binding Energy}

In connection with the above consideration, it seems expedient to consider a thermodynamic probability of existence of hydrogenated graphene - graphane* $\left(\mathrm{CH}_{\text {graphane* }}\right)$ possessing of the values of $\Delta H_{(\mathrm{C}-\mathrm{H}) \text { graphane }} \approx 2.6 \mathrm{eV}[3-5,12,13,18$ $21]$ and $\Delta H_{\text {(C-C)graphane* }} \approx 4.9 \mathrm{eV}[18-21]$. This corresponds to a very high binding (cohesive) energy $\left(\Delta H_{\text {bind.(graphane* }}\right) \approx 10$ $\mathrm{eV} /$ atom, in comparison with those considered above for theoretical graphanes $[3,4,25]$. Because of such thermodynamic probability, it is necessary to take into consideration two more additional reactions:

$\mathrm{C}_{\text {(gas) }} \rightarrow \mathrm{C}_{\text {(graphene) }}\left(\Delta H_{10}\right)$
$\mathrm{C}_{\text {(gas) }}+\mathrm{H}_{\text {(gas) }} \rightarrow \mathrm{CH}_{\text {(graphane*) }}\left(\Delta H_{11}\right)$

where $\Delta H_{10}$ and $\Delta H_{11}$ are the standard energy (enthalpy) changes.

Reaction (11) can be presented as a sum of reaction (2), applied for graphane* as $\left(2^{*}\right)$ with the standard energy change $\Delta H_{2^{*}}$, as well as reaction (10), resulting in the following equation:

$\Delta H_{11}=\left(\Delta H_{2^{*}}+\Delta H_{10}\right)$

Substituting in Eq. (12) the above considered values of $\Delta H_{2^{*}} \approx \Delta H_{2} \approx-\Delta H_{\mathrm{C}-\mathrm{H} \text { (membr.) }}=-2.6 \pm 0.1 \mathrm{eV} /$ atom and $\Delta H_{10} \approx$ $-\Delta H_{\text {cohes.(graphene) }} \approx-\Delta H_{\text {subl.(graphite) }}=-7.41 \pm 0.05 \mathrm{eV} /$ atom, one can obtain a desired value of $\Delta H_{11}=-10.0 \pm 0.1 \mathrm{eV} /$ atom. 
The quantity of $-\Delta H_{11}$ corresponds to the binding (cohesive) energy of graphane* $\left(-\Delta H_{11}=\Delta H_{\text {bind.(graphane*) }}=\right.$ $\left.\Delta H_{\text {cohes.(graphane*) }}\right)$. The quantity $-\Delta H_{11}$ characterizes the breakdown energy of one (C-H) $s p^{3}$-like bond and $1.5(\mathrm{C}-\mathrm{C}) s p^{3}-$ like bonds, relevant to breaking away of one hydrogen atom and one neighboring carbon atom from the material:

$$
\Delta H_{11}=-\Delta H_{\text {bind.(graphane*) }}=-\Delta H_{(\mathrm{C}-\mathrm{H}) \text { graphane* }}-1.5 \Delta H_{(\mathrm{C}-\mathrm{C}) \text { graphane* }}
$$

where $\Delta H_{(\mathrm{C}-\mathrm{H}) \text { graphane* }}$ - the break-down energy of $\mathrm{C}-\mathrm{H} s p^{3}$ bond in graphane*, relevant to the breaking away of one hydrogen atom from the material; $\Delta H_{\text {(C-C)graphane* }}$ - the breakdown energy of C-C $s p^{3}$ bonds in graphane*.

Hence, substituting in Eq. (13) the above noted $\Delta H_{\text {(C- }}$ H)graphane* value, one can evaluate the desired value of $\Delta H_{(\mathrm{C}-}$ C)graphane* $\approx 4.9 \mathrm{eV}$, which coincides (within the errors) with the analogical values for perfect graphene and perfect graphite. The same value of $\Delta H_{(\mathrm{C}-\mathrm{C})} \approx 4.9 \mathrm{eV}$ can be evaluated in a similar manner, i.e., for hydrogenated (up to composition $\mathrm{C}_{2} \mathrm{H}$ ) single-walled carbon nanotubes* and hydrofullerene* $\mathrm{C}_{60} \mathrm{H}_{36}$. Comparing of the obtained values of $\Delta H_{(\mathrm{C}-\mathrm{C}) \text { graphane*, }}$ $\Delta H_{\text {(C-C)nanotubes* }}, \Delta H_{\text {(C-C)hydrofullerene* }}, \Delta H_{\text {(C-C)graphene }}$ and $\Delta H_{\text {(C- }}$ C)graphite show that the elastic and intrinsic strength properties (and particularly Young's modulus $(E)$ ) of graphane*-like nanostructures can be rather close to those for graphene. In connection with this, it is relevant to note that a unique experimental value from work [48] of a Young's modulus of graphene is $E_{\text {graphene }}=1.0$ terapascal.

As was noted in [5], when a hydrogenated graphene membrane has no free boundaries (a rigidly fixed membrane) in the expanded regions of it, the lattice is stretched isotropically by nearly $10 \%$ (i.e., the elastic deformation degree $\varepsilon_{\text {fix.membr. }} \approx 0.1$ ) with respect to the pristine graphene. This amount of stretching $(\varepsilon \approx 0.1)$ is close to the limit of possible elastic deformations in graphene [48], and indeed it has been observed [5] that some of their membranes rupture during hydrogenation. It is believed [5] that the stretched regions are likely to remain non-hydrogenated. They also found that instead of exhibiting random stretching, hydrogenated graphene membranes normally split into domain-like regions of the size of the order of $1 \mu \mathrm{m}$, and that the annealing of such membranes led to complete recovery of the periodicy in both stretched and compressed domains [5].

By using the experimental value [5] of the degree of elastic deformation $\left(\varepsilon_{\text {fix.membr. }} \approx 0.1\right)$ of the hydrogenated fixed graphene membranes, and the experimental value $[5,48]$ of a Young's modulus of graphene $\left(E_{\text {graphene }}=1.0 \mathrm{TPa}\right)$, one can evaluate (within Hooke's law approximation) the stretching stress value $\left(\sigma_{\text {fix.membr. }} \approx\left(\varepsilon_{\text {fix.membr. }} E_{\text {graphene }}\right) \approx 0.1 \mathrm{TPa}\right)$ in the expanded regions (domains or grains) of the material [5]. This analytical result in this study is consistent with the analytical results of the related data considered from [15-21], relevant to the possibility of the existence of hydrogenated graphane*-like nanostructures possessing of a Young's modulus value close to that of graphene ( $E_{\text {graphane }} * E_{\text {graphene }}$ $=1.0 \mathrm{TPa}$ ).

\subsection{Consideration of Data on Hydrogen Desorption in the Hydrogenated Mono- and bi-layer Epitaxial Gra- phene Samples}

In [5], both the graphene membrane samples considered above, and the epitaxial graphene and bi-graphene samples on substrate $\mathrm{SiO}_{2}$ were exposed to a cold hydrogen dc plasma for 2 hours to reach the saturation in the measured characteristics. They used a low-pressure $(0.1 \mathrm{mbar})$ hydrogen-argon mixture of $10 \% \mathrm{H}_{2}$. Raman spectra for hydrogenated and subsequently annealed graphene membranes are rather similar to those for epitaxial graphene samples, but with some notable differences. If hydrogenated simultaneously for 1 hour, and before reaching the saturation (a partial hydrogenation), the D peak area for a membrane was two factors greater than the area for graphene on a substrate, which indicates the formation of twice as many C-H $s p^{3}$ bonds in the membrane. This result also agrees with the general expectation that atomic hydrogen attaches to both sides of the membranes. Moreover, the D peak area became up to about three times greater than the $\mathrm{G}$ peak area after prolonged exposures (for 2 hours, a near-complete hydrogenation) of membranes to atomic hydrogen. The integrated intensity area of the D peak corresponding to the adsorbed hydrogen saturation concentration in the graphene membranes is larger by a factor of about 3 for the area of the $\mathrm{D}$ peak, corresponding to the hydrogen concentration in the epitaxial graphene samples. This may be related to some partial hydrogenation localized in some defected nanoregions [33-42, 49] of the epitaxial graphene samples even after the prolonged ( 3 hour) exposures, i.e. after reaching their near-saturation. It is expedient to note that in [5], the absolute values of the adsorbed hydrogen concentration $\left(C_{0}\right)$ were neither considered for the hydrogenated graphene membranes, nor for the hydrogenated epitaxial graphene samples.

According to a private communication from D.C. Elias, a near-complete desorption of hydrogen $\left(-\Delta C / C_{0} \approx 0.95\right)$ from a hydrogenated epitaxial graphene on a substrate $\mathrm{SiO}_{2}$ (Fig. 2A) has been achieved by annealing it in $90 \% \mathrm{Ar} / 10 \% \mathrm{H}_{2}$ mixture at $T=573 \mathrm{~K}$ for 2 hours (i.e., $\tau_{0.95 \text { (epitax.)573K }}=7.2 \cdot 10^{3}$ s). Hence, by using Eq. (8), one can evaluate the value of $\tau_{0.63(\text { epitax.) } 573 \mathrm{~K}}=2.4 \cdot 10^{3} \mathrm{~s}$ corresponding to data [5] for the epitaxial graphene samples, which is about six orders less than the evaluated value of $\tau_{0.63(\mathrm{membr}) 573 \mathrm{~K}}=1.5 \cdot 10^{9} \mathrm{~s}$ corresponding to data [5] for the membrane graphene samples.

Also, the changes in Raman spectra of graphene [5] caused by hydrogenation were rather similar in respect to locations of $\mathrm{D}, \mathrm{G}, \mathrm{D}^{\prime}, 2 \mathrm{D}$ and $\left(\mathrm{D}+\mathrm{D}^{\prime}\right)$ peaks, both for the epitaxial graphene on $\mathrm{SiO}_{2}$ and for the free-standing graphene membrane. Hence, one can suppose that the kinetic quantities $\left(K_{0}\right.$ and $\left.v\right)$ for the the epitaxial graphene on $\mathrm{SiO}_{2}$ are close to those for the free-standing graphene membrane, ie., $K_{0(\text { (epitax })}=v_{\text {C-H(epitax. })} \approx K_{0(\text { membr) }}=v_{\text {C-H(membr. })} \approx 5 \cdot 10^{13} \mathrm{~s}^{-1}$. Then, by substituting in Eq. (9) the values of $K=K_{\text {(epitax.)573K }}$ $=1 / \tau_{0.63 \text { (epitax.)573K }}$ corresponding to data [5] for the epitaxial samples and the above considered value of $K_{0} \approx K_{0 \text { (membr.), }}$, one can evaluate the desorption activation energy for the epitaxial samples [5] in question $\left(\Delta H_{\text {des.(epitax.) }}=\Delta H_{\mathrm{C}-\mathrm{H}(\text { epitax. })} \approx\right.$ $2.0 \mathrm{eV}$ ). Here, the case is supposed of a non-diffusion-ratelimiting kinetics, when Eq. (9) corresponds to the PolanyiWigner one [14]. Certainly, these tentative thermodynamic characteristics of the hydrogenated samples [5] of epitaxial graphene on a substrate $\mathrm{SiO}_{2}$ could be unambiguosly confirmed and/or modified by receiving and treating within Eqs. $(8,9)$ of the experimental data (similar to [5]) on $\tau_{0.63 \text { (epitax.) }}$ at several annealing temperatures. 
It is now easy also to state that: 1) these analytical results are not consistent with the mass spectrometry data on thermal desorption of hydrogen from a specially prepared singleside graphane [5]; and 2) they cannot be described in the framework of the theoretical models and characteristics of thermal stability of single-side hydrogenated graphene [6] or graphone [9]. According to the further considerations in this study, it may be a hydrogen desorption case of a diffusion rate limiting kinetics, when $K_{0} \neq v$, and Eq. (9) does not correspond to the Polanyi-Wigner one [14].

By using the method [14] of treatment of thermal desorption (TDS) spectra, relevant to the mass spectrometry data [5] on thermal desorption of hydrogen from a specially prepared single-side graphane (under heating from room temperature to $573 \mathrm{~K}$ for 6 minutes), one can obtain the following results: 1) the total integrated area of the thermal desorption spectra corresponds to $\sim 2 \cdot 10^{-8} \mathrm{~g}$ of desorbed hydrogen; 2 ) the TDS spectra can be approximated by three thermodesorption (TDS) peaks (\# 1 , \# 2 and \# 3); 3) TDS peak \# 1 ( $\sim 30 \%$ of the total area, $T_{\max \# 1} \approx 370 \mathrm{~K}$ ) can be characterized by the activation energy of $E_{\mathrm{TDS}-\text { peak } \# 1}=0.6 \pm 0.3 \mathrm{eV}$ and by the per-exponential factor of the reaction rate constant $\left.K_{0 \text { (TDS-peak \# } 1)} \approx 2 \cdot 10^{7} \mathrm{~s}^{-1} ; 4\right)$ TDS peak \# $2(\sim 15 \%$ of the total area, $T_{\max \# 2} \approx 445 \mathrm{~K}$ ) can be characterized by the activation energy $E_{\mathrm{TDS} \text {-peak \#2 }}=0.6 \pm 0.3 \mathrm{eV}$, and by the per-exponential factor of the reaction rate constant $K_{0 \text { (TDS-peak \# 2) }} \approx 1 \cdot 10^{6} \mathrm{~s}^{-1}$; and 5) TDS peak \# $3\left(\sim 55 \%\right.$ of the total area, $T_{\max \# 3} \approx 540$ K) can be characterized by the activation energy $E_{\text {TDS-peak \# } 3}$ $=0.23 \pm 0.05 \mathrm{eV}$ and by the per-exponential factor of the reaction rate constant $K_{0 \text { (TDS-peak \# } 3)} \approx 2.4 \mathrm{~s}^{-1}$. These analytical results show that all three of the above noted thermal desorption (TDS) processes (\# $1_{\mathrm{TDS}}$, \# $2_{\mathrm{TDS}}$ and \# $3_{\mathrm{TDS}}$ ) may be related to a hydrogen desorption case of a diffusion-ratelimiting kinetics [14], when in Eq. 9 the value of $K_{0} \approx\left(D_{0 \text { app. }}\right.$. $\left./ L^{2}\right)$ and the value of $\Delta H_{\text {des. }}=Q_{\text {app. }}$, where $D_{\text {aapp }}$ is the perexponent factor of the apparent diffusion coefficient $D_{\text {app. }}=$ $D_{0 \text { app. }} \exp \left(-Q_{\text {app. }} / k_{\mathrm{B}} T\right), L$ is the characteristic diffusional size (length), and $Q_{\text {app. }}$ is the apparent diffusion activation energy.

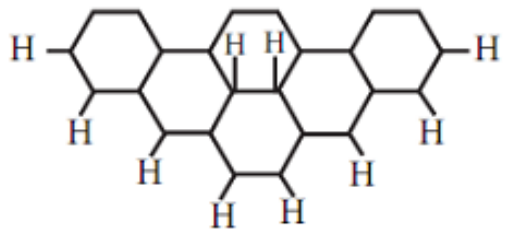

E

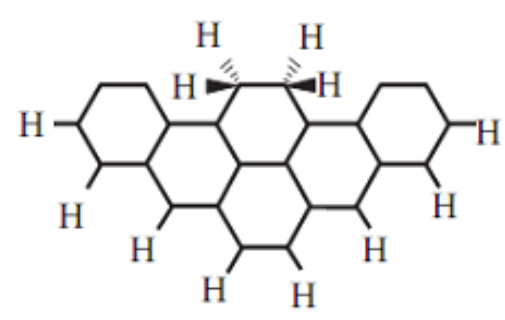

G
TDS process \# 3 TDS may be related to TDS process (or peak) I in [14, 18-21], for which the apparent diffusion activation energy is $Q_{\text {app.I }} \approx 0.2 \mathrm{eV} \approx E_{\mathrm{TDS} \text {-peak \# } 3}$ and $D_{0 \text { app.I }} \approx$ $3 \cdot 10^{-3} \mathrm{~cm}^{2} / \mathrm{s}$. Hence, one can evaluate the quantity of $L_{\mathrm{TDS}-\text { peak }}$ \# $3 \approx\left(D_{\text {0app.I }} / K_{0 \text { (TDS-peak \# 3) }}\right)^{1 / 2} \approx 3.5 \cdot 10^{-3} \mathrm{~cm}$, which may be related to the linear size of the graphene specimens. Thus, TDS process \# 3 TDS may be related to chemisorption models "H" and/or "G" (Fig. 1) corresponding to TDS process (or peak) $\mathrm{I}$ in $[14,18-21]$.

TDS processes \# $1_{\mathrm{TDS}}$ [5] and \# $2_{\mathrm{TDS}}$ [5] may be related, (in some extent) to chemisorption models " $\mathrm{H}$ " and/or " $\mathrm{G}$ " (Fig. 1 [50]). Model " $\mathrm{H}$ " corresponds to TDS process (or peak) II in [14, 16, 18-21], for which the apparent diffusion activation energy is $Q_{\text {app.II }} \approx 1.2 \mathrm{eV}$ that is comparatively close to $E_{\mathrm{TDS}-\text { peak \# 1.2. }}$. Obviously, chemisorption models " $\mathrm{H}$ " and/or "G" (Fig. 1) can be applied only for the defected nano-regions in the epitaxial graphene flakes [5], for instance, as vacancies, grain boundaries (domains), and/or triple junctions (nodes) of the grain-boundary network [33-42, 49]), where the dangling carbon bonds can occur.

It is important to note that in Items 2.1-2.3 chemisorption of atomic hydrogen on graphene membranes [3-5] may be related to model " $\mathrm{F} *$ " $[14,16,18-21]$, which is relevant to chemisorption of a single hydrogen atom on one of the carbon atoms possessing of 3 unoccupied (by hydrogen) nearest carbons, but not two hydrogen atoms on two carbons, as seen in model "F" (Fig. 1). Model " $F$ ") is characterized [14, 16, 18 -21] by the quantity of $\Delta H_{(\mathrm{C}-\mathrm{H})^{\prime} \mathrm{F} *} \approx 2.5 \mathrm{eV}$, which coincides with the similar quantities of graphanes [3-5].

In work [5], the same hydrogenation procedures of the 2 hour long expositions have been applied, as well as bilayer epitaxial graphene on $\mathrm{SiO}_{2} / \mathrm{Si}$ wafer. Bilayer samples showed little change in their charge carrier mobility and a small D Raman peak, compared to the single-layer epitaxial graphene on $\mathrm{SiO}_{2} / \mathrm{Si}$ wafer exposed to the same hydrogenation procedures. The authors believe that higher rigidity of bilayers suppressed their rippling, thus reducing the probability of hydrogen adsorption.<smiles>FCC1CCC2C=CC3CCCC4CC1CC2CC34</smiles>

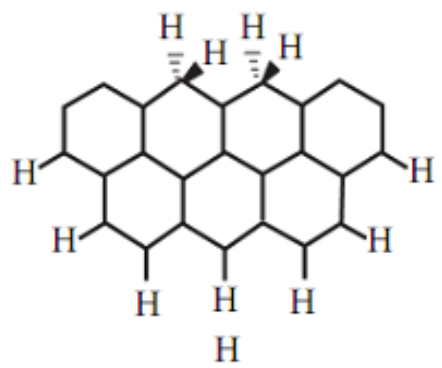

Fig. (1). Schematics (used in [14, 16, 18-21]) of some theoretical models (ab initio molecular orbital calculations [50]) of chemisorption of atomic hydrogen on graphite on the basal and edge planes. 
In this study, further consideration must be given to some other known experimental data that on hydrogenation and thermal stability characteristics of mono-layer, bi-layer and three-layer epitaxial graphene systems play an important role some defects found in graphene networks [33-42, 49], relevant to the probability of hydrogen adsorption and the permeability of graphene networks for atomic hydrogen. The analytical results of Item 2 are presented in Table $\mathbf{1}$.

\section{ANALYSIS AND COMPARISON OF RELEVANT EXPERIMENTAL DATA}

3.1. Analysis of the Raman Spectroscopy Data on Thermal Desorption of Hydrogen from Hydrogenated Graphene Flakes

In [51], it is reported that the hydrogenation of single and bilayer graphene flakes by an argon-hydrogen plasma produced in a reactive ion etching (RIE) system. They analyzed two cases: one where the graphene flakes were electrically insulated from the chamber electrodes by the $\mathrm{SiO}_{2}$ substrate, and the other where the flakes were in electrical contact with the source electrode (a graphene device). Electronic transport measurements in combination with Raman spectroscopy were used to link the electric mean free path to the optically extracted defect concentration, which is related to the defect distance $\left(L_{\text {def. }}\right)$. This showed that under the chosen plasma conditions, the process does not introduce considerable damage to the graphene sheet, and that a rather partial hydrogenation $\left(C_{\mathrm{H}} \leq 0.05 \%\right)$ occurs primarily due to the hydrogen ions from the plasma, and not due to fragmentation of water adsorbates on the graphene surface by highly accelerated plasma electrons. To quantify the level of hydrogenation, they used the integrated intensity ratio $\left(I_{\mathrm{D}} / I_{\mathrm{G}}\right)$ of Raman bands. The hydrogen coverage $\left(C_{\mathrm{H}}\right)$ determined from the defect distance $\left(L_{\text {def. }}\right)$ did not exceed $\sim 0.05 \%$.

In [51], they also performed the heating of the hydrogenated single graphene flakes (on the $\mathrm{SiO}_{2}$ substrate) in a nitrogen environment, on a hot-plate, and with temperatures ranging from $348 \mathrm{~K}$ to $548 \mathrm{~K}$, each time $(\Delta t)$ of 1 min. Heating results decrease the integrated intensity ratio $\left(I_{\mathrm{D}} / I_{\mathrm{G}}\right)$ of Raman bands. Within a formal kinetics approach $[14,46]$, the averaged kinetic data for samples of 10, 20 and 40 minute exposure can be treated by using Eq. (7) transformed to a more suitable form $\left(7^{\prime}\right): K \approx-((\Delta C / \Delta t) / C)$, where $\Delta t=60 \mathrm{~s}$, $\Delta C$ and $C$ are determined from [51]. This resulted in finding 5 values of the reaction (desorption) rate constant $(K)$ for 5 temperatures $(T=348,398,448,498$ and $548 \mathrm{~K})$. Their temperature dependence is described by Eq. (9). Hence, the de-

Table 1. Analytical (an.) Results of Item 2

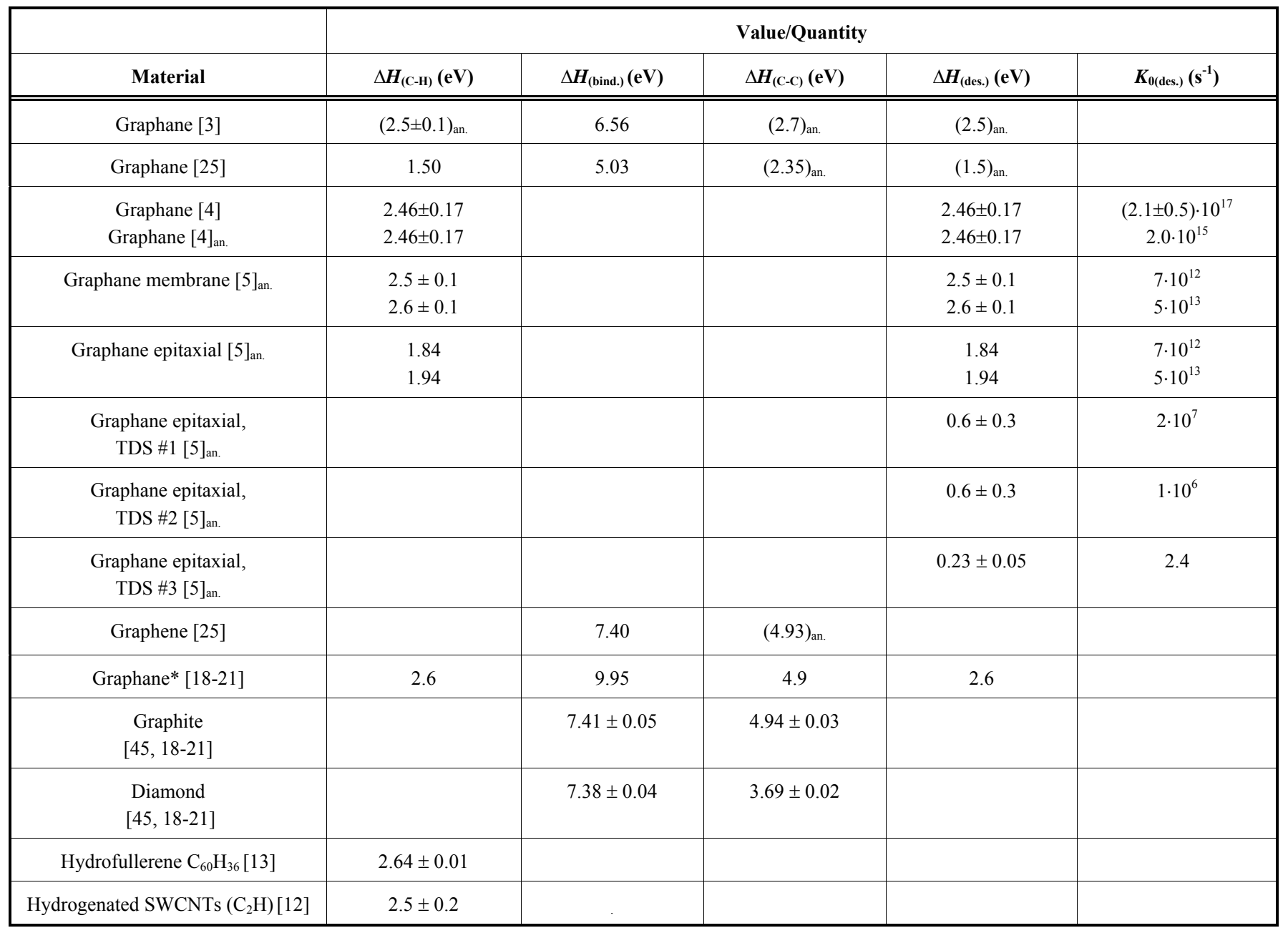


sired quantities have been determined (Table 2) for the desorption activation energy $\Delta H_{\text {(des.) }}=0.11 \pm 0.07 \mathrm{eV}$, the perexponential factor of the reaction rate constant $K_{0 \text { (des.) }} \approx 0.15$ $\mathrm{s}^{-1}$, and also the desorption time at $553 \mathrm{~K} \tau_{0.63(\text { des. }) 553 \mathrm{~K}} \approx 70 \mathrm{~s}$.

The calculated values of $\Delta H_{\text {(des.)[51] }}$ and $K_{0 \text { (des.) }}$ are close (within the errors) to those for TDS process \# 3 (Table 1) [5]. These two desorption processes may be related to TDS process (or peak) I in [14, 18-21], for which the apparent diffusion activation energy is $Q_{\text {app.I }} \approx 0.2 \mathrm{eV} \approx E_{\text {TDS-peak \#3 }} \approx$ $\Delta H_{\text {(des.) }}$. By taking into account the facts that the RIE exposure regime [51] is characterized by a form of $\left(I_{\mathrm{D}} / I_{\mathrm{G}}\right) \sim L_{\text {def. }}{ }^{-2}$ (for $\left(I_{\mathrm{D}} / I_{\mathrm{G}}\right)<2.5$ and $L_{\text {def }} \approx 11-17 \mathrm{~nm}$ ), and the hydrogen concentration $C_{\mathrm{H}} \leq 5 \cdot 10^{-4}$ is rather small, one can suppose that the hydrogen adsorption centers in the single graphene flakes (on the $\mathrm{SiO}_{2}$ substrate) are related in some point to nanodefects (i.e., vacancies and/or triple junctions (nodes) of the grain-boundary network [33-42, 49]) of diameter $d_{\text {def. }} \approx$ const. In such a model, the quantity $C_{\mathrm{H}}$ can be described satisfactory as:

$C_{\mathrm{H}} \approx n_{\mathrm{H}}\left(d_{\text {def. }}\right)^{2} /\left(L_{\text {def. }}\right)^{2}$

where $n_{\mathrm{H}} \approx$ const. is the number of hydrogen atoms adsorbed by a center; $C_{\mathrm{H}} \sim\left(I_{\mathrm{D}} / I_{\mathrm{G}}\right) \sim L_{\text {def. }^{-2}}$.

It was also found that after the $\mathrm{Ar} / \mathrm{H}_{2}$ plasma exposure, the $\left(I_{\mathrm{D}} / I_{\mathrm{G}}\right)$ ratio for bilayer graphene device is larger than that of the single graphene device. As noted in [51], this observation is in contradiction to the Raman ratios after exposure of graphene to atomic hydrogen (considered in the previous Item 2.4.) and when other defects are introduced.

\subsection{Analysis of the STM and STS Data on Reversible Hydrogenation of Epitaxial Graphene and Graphite Sur- faces}

In [52], the effect of hydrogenation on topography and electronic properties of graphene grown by CVD on top of a nickel surface and high oriented pyrolytical graphite (HOPG) surfaces were studied by scanning tunneling microscopy (STM) and spectroscopy (STS). The surfaces were chemically modified using $40 \mathrm{~min} \mathrm{Ar} / \mathrm{H}_{2}$ plasma (with $3 \mathrm{~W}$ power) treatment. This determined that the hydrogen chemisorption on the surface of graphite/graphene opens on average an energy bandgap of $0.4 \mathrm{eV}$ around the Fermi level. Although the plasma treatment modifies the surface topography in an irreversible way, the change in the electronic properties can be reversed by moderate thermal annealing (for 10 min at $553 \mathrm{~K}$ ), and the samples can be hydrogenated again to yield a similar, but slightly reduced, semiconducting behavior after the second hydrogenation. The data shows that the time of desorption from both the epitaxial graphene/Ni samples and HOPG samples of about $99 \%$ of hydrogen under $553 \mathrm{~K}$ annealing is $\tau_{0.99 \text { (des.) } 553 \mathrm{~K}} \approx 6 \cdot 10^{2} \mathrm{~s}$. Hence, by using Eq. (8), one can evaluate the quantity $\tau_{0.63 \text { (des.) } 553 \mathrm{~K}} \approx 130 \mathrm{~s}$, which is close (within the errors) to the similar quantity of $\tau_{0.63 \text { (des.) } 553 \mathrm{~K}} \approx 70 \mathrm{~s}$ for the epitaxial graphene flakes [51] considered in the previous Item 3.1.

As noted in [53], before the plasma treatment, the graphene grown on nickel by CVD exhibits a Moiré pattern superimposed to the honeycomb lattice of graphene. This is due to the lattice parameter mismatch between the graphene and the nickel surfaces, and thus the characteristic of the most of the epitaxial graphene samples. On the other hand for the hydrogenated CVD graphene, the expected structural changes are twofold [53]. First, the chemisorption of hydrogen atoms will change the $s p^{2}$ hybridization of carbon atoms to tetragonal $s p^{3}$ hybridization, modifying the surface geometry. Second, the impact of heavy Ar ions, present in the plasma, could also modify the surface by inducing geometrical displacement of carbon atoms (rippling graphene surface) or creating vacancies and other defects (for instance, grain or domain boundaries) [33-42, 49]. The topography image of the surface CVD graphene after the extended (40 min) plasma treatment. The nano-order-corrugation increases after the treatment, and there are brighter nano-regions (of about $1 \mathrm{~nm}$ in height and several $\mathrm{nm}$ in diameter) in which the atomic resolution is lost or strongly distorted. It was also found that these bright nano-regions present a semiconducting behavior, while the rest of the surface remains conducting $[52,53]$.

It is reasonable to assume that most of the chemisorbed hydrogen is localized into these bright nano-regions, which have a blister-like form. Moreover, it is also reasonable to assume that the monolayer (single) graphene flakes on the $\mathrm{Ni}$ substrate are permeable to atomic hydrogen only in these defected nano-regions. This problem has been formulated in Item 1 (Introduction). A similar model may be valid and relevant for the HOPG samples [52].

It has been found outthat when graphene is deposited on a $\mathrm{SiO}_{2}$ surface, the charged impurities presented in the graphene/substrate interface produce strong inhomogeneities of the electronic properties of graphene. On the other hand, it has also been shown how homogeneous graphene grown by CVD can be altered by chemical modification of its surface by the chemisoption of hydrogen. It strongly depresses the local conductance at low biases, indicating the opening of a band gap in grapheme $[53,54]$.

The charge inhomogeneities (defects) of epitaxial hydrogenated graphene/ $\mathrm{SiO}_{2}$ samples do not show long range ordering, and the mean spacing between them is $L_{\text {def. }} \approx 20 \mathrm{~nm}$ $[53,54]$. It is reasonable to assume that the charge inhomogeneities (defects) are located at the interface between the $\mathrm{SiO}_{2}$ layer (300 nm thick) and the graphene flake [53, 54]. A similar quantity $\left(L_{\text {def. }} \approx 11-17 \mathrm{~nm},[51]\right)$ ) for the hydrogen adsorption centers in the single graphene flakes on the $\mathrm{SiO}_{2}$ substrate has been considered in Item 3.1.

\subsection{Analysis of the HREELS/LEED Data on Thermal Desorption of Hydrogen from Hydrogenated Graphene on SiC Substrate}

In [55], hydrogenation of deuterium-intercalated quasifree-standing monolayer graphene on $\mathrm{SiC}(0001)$ was obtained and studied with low-energy electron diffraction (LEED) and high-resolution electron energy loss spectroscopy (HREELS). While the carbon honeycomb structure remained intact, it has shown a significant band gap opening in the hydrogenated material. Vibrational spectroscopy evidences for hydrogen chemisorption on the quasi-freestanding graphene has been provided and its thermal stability has been studied. Deuterium intercalation, transforming the buffer layer in quasi-free-standing monolayer graphene (de- 
Table 2. Analytical results of Sections 3.1-3.3

\begin{tabular}{|c|c|c|c|}
\hline Material & \multicolumn{3}{|c|}{ Value/Quantityxx } \\
\hline $\begin{array}{c}\text { Graphene/Ni [52] } \\
\text { HOPG [52] }\end{array}$ & & & $\begin{array}{l}130 \\
130 \\
\end{array}$ \\
\hline (SiC-D/QFMLG) [55] & $2.0 \pm 0.6$ & $1 \cdot 10^{6}$ & \\
\hline
\end{tabular}

noted as $\mathrm{SiC}-\mathrm{D} / \mathrm{QFMLG}$, has been performed with a $\mathrm{D}$ atom exposure of $\sim 5 \cdot 10^{17} \mathrm{~cm}^{-2}$ at a surface temperature of $950 \mathrm{~K}$. Finally, hydrogenation up to saturation of quasi-freestanding monolayer graphene has been performed at room temperature with a $\mathrm{H}$ atom exposure $>3 \cdot 10^{15} \mathrm{~cm}^{-2}$. The latter sample has been denoted as $\mathrm{SiC}-\mathrm{D} / \mathrm{QFMLG}-\mathrm{H}$ to stress the different isotopes used, first, to prepare quasi-free-standing monolayer graphene (the D-intercalation step), and second, to hydrogenate it.

According to a private communication from R. Bisson, the temperature indicated at each point of data [55] corresponds to successive temperature ramp (not linear) of 5 minutes. Within a formal kinetics approach for the first order reactions $[14,46]$, one can treat the above noted points at $T_{\mathrm{i}}$ $=543 \mathrm{~K}, 611 \mathrm{~K}$ and $686 \mathrm{~K}$, by using Eq. (8) transformed to a more suitable form $\left(8^{\prime}\right): K_{\mathrm{i}} \approx-\left(\ln \left(C / C_{0 \mathrm{i}}\right) / t\right)$, where $t=300 \mathrm{~s}$, and the corresponding quantities $C_{0 \mathrm{i}}$ and $C$ are determined from [55]. It resulted in finding values of the reaction (hydrogen desorption from $\mathrm{SiC}-\mathrm{D} / \mathrm{QFMLG}-\mathrm{H}$ samples) rate constant $K_{\mathrm{i}}$ for 3 temperatures $T_{\mathrm{i}}=543,611$ and $686 \mathrm{~K}$. The temperature dependence is described by Eq. (9). Hence, the desired quantities have been determined (Table 2) as the reaction (hydrogen desorption) activation energy $\Delta H_{\text {des.(SiC- }}$ $\mathrm{D} /$ QFMLG-H) $=0.7 \pm 0.2 \mathrm{eV}$, and the per-exponential factor of the reaction rate constant $K_{0 \text { des.(SiC-D/QFMLG-H) }} \approx 9 \cdot 10^{2} \mathrm{~s}^{-1}$. The obtained value of $\Delta H_{\text {des.(SiC-D/QFMLG-H) }}$ is close (within the errors) to the similar ones ( $E_{\mathrm{TDS} \text {-peak \# } 1}$ and $\left.E_{\mathrm{TDS} \text {-peak \# 2 }}\right)$ [5] for TDS processes \# 1 and \# 2 (Item 2.4, Table 1). But the obtained value $K_{0 \text { des.(SiC-D/QFMLG-H) }}$ differs by several orders from the similar ones $K_{0 \text { des.(TDS-peak \# 1) }}$ and $K_{0 \text { des.(TDS-peak \# 2) }}$ [5] for TDS processes \# 1 and \# 2 (Item 2.4, Table 1). Nevertheless, these three desorption processes may be (in some extent) related to chemisorption models " $\mathrm{H}$ " and/or "G" (Fig. 1). Model " $\mathrm{H}$ " is related to TDS process II in [14, 18-21], for which the apparent diffusion activation energy is $Q_{\text {app.II }} \approx 1.2$ eV.

In the same way, one can treat the points from data [55] at $T_{\mathrm{i}}=1010,1120$ and $1200 \mathrm{~K}$, which one are related to the intercalated deuterium desorption from $\mathrm{SiC}-\mathrm{D} / \mathrm{QFMLG}$ samples. This results in finding the desired quantities (Table 2): the reaction (deuterium desorption) activation energy $\Delta H_{\text {des.(SiC-D/QFMLG) }}=2.0 \pm 0.6 \mathrm{eV}$, and the per-exponential factor of the reaction rate constant $K_{0 \text { des.(SiC-D/QFMLG) }} \approx 1 \cdot 10^{6} \mathrm{~s}^{-}$ 1 . The authors supposed that it may be related to hydrogen chemisorbed on the silicon atoms of the SiC substrate below the graphene plane [55]. Formally, this desorption process (of a diffusion-limiting character) may be described similarly to TDS process (peak) III in $[14,18-21]$, and the apparent diffusion activation energy may be close to the break-down energy of the Si-H bonds. As concluded in [55], the exact intercalation mechanism of hydrogen diffusion through the anchored graphene lattice, at a defect or at a boundary of the anchored graphene layer, remains an open question.

It is reasonable to assume that the quasi-free-standing monolayer graphene on the $\mathrm{SiC}-\mathrm{D}$ substrate is permeable to atomic hydrogen (at room temperature) in some defect nanoregions (probably, in vacancies and/or triple junctions (nodes) of the grain-boundary network [33-42, 49]). It would be expedient to note that the HREELS data [55] on bending and stretching vibration $\mathrm{C}-\mathrm{H}$ frequencies in SiC-D/QFMLG$\mathrm{H}$ samples $\left(153 \mathrm{meV}\left(3.7 \cdot 10^{13} \mathrm{~s}^{-1}\right)\right.$ and $331 \mathrm{meV}\left(8.0 \cdot 10^{13}\right.$ $\mathrm{s}^{-1}$ ), respectively) are consistent with those considered in Section 2.2, related to the HREELS data [47] for the epitaxial graphene.

The obtained characteristics (Table 2) of desorption processes $[51,52,55]$ show that these processes may be of a diffusion-rate-controlling character [14].

\subsection{Analysis of the Raman Spectroscopy Data on Ther- mal Desorption of Hydrogen from Hydrogenated Gra- phene Layers on $\mathrm{SiO}_{2}$ Substrate}

In [56], graphene layers on $\mathrm{SiO}_{2} / \mathrm{Si}$ substrate have been chemically decorated by radio frequency hydrogen plasma (the power of 5-15 W, the pressure of 1 Tor) treatment for 1 min. As seen from the investigation of hydrogen coverage by Raman spectroscopy and micro-X-ray photoelectron spectroscopy characterization demonstrates that the hydrogenation of a single layer graphene on $\mathrm{SiO}_{2} / \mathrm{Si}$ substrate is much less feasible than that of bilayer and multilayer graphene. Both the hydrogenation and dehydrogenation processes of the graphene layers are controlled by the corresponding energy barriers, which show significant dependence on the number of layers. These results [56] on bilayer graphene/ $\mathrm{SiO}_{2} / \mathrm{Si}$ are in contradiction to the results [5] on a negligible hydrogenation of bilayer epitaxial graphene on $\mathrm{SiO}_{2} / \mathrm{Si}$ wafer, when obviously other defects are produced.

Within a formal kinetics approach $[14,46]$, the kinetic data [56] for single layer graphene samples (1LG-5W and $1 \mathrm{LG}-15 \mathrm{~W}$ ones) can be treated. Eq. (7) is used to transform into a more suitable form $\left(7^{\prime}\right): K \approx-((\Delta C / \Delta t) / C)$, where $\Delta t=$ $1800 \mathrm{~s}$, and $\Delta C$ and $C$ are determined from [56]. 
It results in finding for $1 \mathrm{LG}-15 \mathrm{~W}$ samples three values of the I [56] reaction rate constant $K_{\mathrm{I}(1 \mathrm{LG}-15 \mathrm{~W})}$ for three temperatures $(T=373,398$ and $423 \mathrm{~K})$, and three values of the II [56] reaction rate constant $K_{\mathrm{II}(1 \mathrm{LG}-15 \mathrm{~W})}$ for three temperatures $(T=523,573$ and $623 \mathrm{~K})$. Hence, by using Eq. (9), the following values for $1 \mathrm{LG}-15 \mathrm{~W}$ samples have been determined (Table 3): the I reaction activation energy $\Delta H_{\text {des.I(1LG-15W) }}=$ $0.6 \pm 0.2 \mathrm{eV}$, the per-exponential factor of the I reaction rate constant $K_{0 \text { des.I(ILG-15W) }} \approx 2 \cdot 10^{4} \mathrm{~s}^{-1}$, the II reaction activation energy $\Delta H_{\text {des.II[(1LG-15W) }}=0.19 \pm 0.07 \mathrm{eV}$, and the perexponential factor of the II reaction rate constant $K_{0 \text { des.III(1LG- }}$ $15 \mathrm{~W}) \approx 3 \cdot 10^{-2} \mathrm{~s}^{-1}$. It also resulted in finding for $1 \mathrm{LG}-5 \mathrm{~W}$ sample 4 values of the $\mathrm{I}_{[56]}$ reaction rate constant $K_{\mathrm{I}(1 \mathrm{LG}-5 \mathrm{~W})}$ for 4 temperatures $(T=348,373,398$ and $423 \mathrm{~K})$, and 2 values of the $\mathrm{II}_{[56]}$ reaction rate constant $K_{\mathrm{II}(1 \mathrm{LG}-5 \mathrm{~W})}$ for 2 temperatures $(T=523$ and $573 \mathrm{~K})$. Therefore by using Eq. (9), one can evaluate the desired quantities for $1 \mathrm{LG}-5 \mathrm{~W}$ specimens (Table 3): the I reaction activation energy $\Delta H_{\text {des.I(ILG-5W) }}=0.15 \pm$ $0.04 \mathrm{eV}$, the per-exponential factor of the I reaction rate constant $K_{0 \text { des.I[(1LG-5W) }} \approx 2 \cdot 10^{-2} \mathrm{~s}^{-1}$, the II reaction activation energy $\Delta H_{\text {des.II(1LG-5W) }}=0.31 \pm 0.07 \mathrm{eV}$, and the perexponential factor of the II reaction rate constant $K_{0 \text { des.II(1LG- }}$ 5W) $\approx 0.5 \mathrm{~s}^{-1}$.

A similar treatment of the kinetic data for bilayer graphene $2 \mathrm{LG}-15 \mathrm{~W}$ samples resulted in obtaining 4 values of the II reaction rate constant $K_{\mathrm{II}(2 \mathrm{LG}-15 \mathrm{~W})}$ for 4 temperatures ( $T$ $=623,673,723$ and $773 \mathrm{~K}$ ). Hence, by using Eq. (9), the following desired values are found (Table 3 ): the II reaction activation energy $\Delta H_{\text {des.II } 2 \mathrm{LG}-15 \mathrm{~W})}=0.9 \pm 0.3 \mathrm{eV}$, the perexponential factor of the II reaction rate constant $K_{0 \text { des.II(2LG- }}$ $15 \mathrm{~W}) \approx 1 \cdot 10^{3} \mathrm{~s}^{-1}[56]$.

A similar treatment of the kinetic data from [56] for bilayer graphene $2 \mathrm{LG}-5 \mathrm{~W}$ samples results in obtaining 4 values for the I reaction rate constant $K_{\mathrm{I}(2 \mathrm{LG}-5 \mathrm{~W})}$ for 4 temperatures $(T=348,373,398$ and $423 \mathrm{~K})$, and 3 values for the II reaction rate constant $K_{\mathrm{II}(2 \mathrm{LG}-5 \mathrm{~W})}$ for 3 temperatures $(T=573$, 623 and $673 \mathrm{~K}$ ). Their temperature dependence is described by Eq. (9). Hence, one can evaluate the following desired values (Table 3): the I reaction activation energy $\Delta H_{\text {des.I[(2LG- }}$
${ }_{5 \mathrm{~W})}=0.50 \pm 0.15 \mathrm{eV}$, the per-exponential factor of the I reaction rate constant $K_{0 \text { des.I(2LG-5W) }} \approx 2 \cdot 10^{3} \mathrm{~s}^{-1}$, the II reaction activation energy $\Delta H_{\text {des.II(2LG-5W) }}=0.40 \pm 0.15 \mathrm{eV}$, and the perexponential factor of the II reaction rate constant $K_{0 \text { des.II(2LG- }}$ $5 \mathrm{~W}) \approx 1 \mathrm{~s}^{-1}$.

The obtained characteristics (Table 3 ) of the desorption processes I and II show that these processes may be of a diffusion-rate-controlling character [14].

\subsection{Analysis of TDS and STM Data on HOPG Treated by Deuterium}

In [57], the results are present of a scanning tunneling microscopy (STM) study of graphite (HOPG) treated by atomic deuterium, which reveals the existence of two distinct hydrogen dimer states on graphite basal planes. The density functional theory calculations allow them to identify the atomic structure of these states and to determine their recombination and desorption pathways. As predicted, the direct recombination is only possible from one of the two dimer states. In conclusion, this results in an increased stability of one dimer species, and explains the puzzling double peak structure observed in temperature programmed desorption (TPD) TDS - spectra for hydrogen on graphite [57].

In the present study, by using the described in [14] the method of TPD (TDS) peaks treatment (for the first order reactions), relevant to TPD (TDS) peak I [57] ( 65\% of the total area, $T_{\max } \approx 473 \mathrm{~K}$ ). The values have been obtained from the reaction I rate constant $\left(K_{\mathrm{I}}=1 / \tau_{0.63 \text { (des.) })}\right)$ for several temperatures $(T=458,482$ and $496 \mathrm{~K})$. Their temperature dependence is described by Eq. (9). Hence, the desired values are defined as follows (Table 3): the reaction (desorption) I activation energy $\Delta H_{\text {(des.)I }}=0.6 \pm 0.2 \mathrm{eV}$, and the perexponential factor of the reaction I rate constant $K_{0 \text { (des.)I }} \approx$ $1.5 \cdot 10^{4} \mathrm{~s}^{-1}$. In a similar way, relevant to TPD (TDS) peak II [57] $\left(\sim 35 \%\right.$ of the total area, $\left.T_{\operatorname{maxII}} \approx 588 \mathrm{~K}\right)$ ) [57], the values have been obtained of the reaction II rate constant $\left(K_{\mathrm{II}}=\right.$

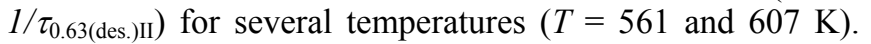
Hence, the desired values are defined as follows (Table $\mathbf{3}$ ):

Table 3. Some Analytical (an.) Results of Items 3.4, 3.5, 3.6, 3.7 and 4

\begin{tabular}{|c|c|c|c|c|}
\hline \multirow[b]{2}{*}{ Samples } & \multicolumn{4}{|c|}{ Values / Quantities } \\
\hline & $\begin{array}{l}\Delta H_{\text {(des.)I }} \\
(\mathrm{eV})\end{array}$ & $\begin{array}{c}K_{0(\text { des. }) \mathrm{I}} \\
\left(\mathrm{s}^{-1}\right)\end{array}$ & $\begin{array}{c}\Delta H_{\text {(des.)II }} \\
(\mathrm{eV})\end{array}$ & $\begin{array}{c}K_{0 \text { (des.)II }} \\
\left(\mathrm{s}^{-1}\right)\end{array}$ \\
\hline 1LG-15W (graphene) [56] & $0.6 \pm 0.2$ & $2 \cdot 10^{4}$ & $0.19 \pm 0.07$ & $3 \cdot 10^{-2}$ \\
\hline 2LG-15W(bi-graphene)[56] & & & $0.9 \pm 0.3$ & $1 \cdot 10^{3}$ \\
\hline 2LG-5W (bi-graphene) [56] & $0.50 \pm 0.15$ & $2 \cdot 10^{3}$ & $0.40 \pm 0.15$ & 1 \\
\hline HOPG[57], TDS-peaks I, II & $0.6 \pm 0.2$ & $1.5 \cdot 10^{4}$ & $1.0 \pm 0.3$ & $2 \cdot 10^{6}$ \\
\hline Graphene/SiC [17] & & & 3.6 & $2 \cdot 10^{14}$ \\
\hline $\begin{array}{l}\text { HOPG[59], TDS-peaks I, II } \\
\text { HOPG [59], TDS-peak I }\end{array}$ & $\begin{array}{c}2.4[59] \\
(2.4 \pm 0.5)_{\text {an. }}\end{array}$ & $\left(2 \cdot 10^{10}\right)_{\text {an }}$ & $4.1[59]$ & \\
\hline
\end{tabular}


the reaction (desorption) II activation energy $\Delta H_{\text {(des.)II }}=1.0 \pm$ $0.3 \mathrm{eV}$, and the per-exponential factor of the reaction II rate constant $K_{0 \text { (des.)II }} \approx 2 \cdot 10^{6} \mathrm{~s}^{-1}$.

The obtained characteristics (Table 3 ) of the desorption processes I and II show that these processes probably are of a diffusion-rate-controlling character [14]. In a diffusion-ratecontrolling case, these processes can not be described by using the Polanyi-Wigner equation (as it has been done in [57]). The observed in [57] "nano-dimer states" or "nanoprotrusions" may be related to the defected nano-regions, probably, as grain (domain) boundaries [49] and/or triple and other junctions (nodes) of the grain-boundary network in the HOPG samples. Some defected nano-regions at the grain boundary network (hydrogen adsorption centers \# I, mainly, the "dimer B" structures) can be related to TPD (TDS) peak I, the others (hydrogen adsorption centers \# II, mainly, the "dimer A" structures) to TPD (TDS) peak II.

In STM data [57], one can imagine some grain boundary network (with the grain size of about 2-5 nm) decorated (in some nano-regions at grain boundaries) by some bright nano-protrusions. Similar "nano-protrusions" are observed and in graphene/ $\mathrm{SiC}$ systems [17, 58].

In STM data [58], one can also imagine some grain boundary network in the hydrogenated graphene samples (with the grain size of about 2-5 nm) decorated in some nano-regions at grain boundaries, by some bright nanoprotrusions [33-42, 49].

In [58], hydrogenation was studied by a beam of atomic deuterium $10^{12}-10^{13} \mathrm{~cm}^{-2} \mathrm{~s}^{-1}$ (corresponding to $P_{\mathrm{D}} \approx 10^{-4} \mathrm{~Pa}$ ) at $1600 \mathrm{~K}$, and the time of exposure of 5-90 s, for single graphene on SiC-substrate. The formation of graphene blisters were observed, and intercalated with hydrogen in them, similar to those observed on graphite [57] and graphene/ $\mathrm{SiO}_{2}$ [17].

The blisters [58] disappeared after keeping the samples in vacuum at $1073 \mathrm{~K}$ ( $15 \mathrm{~min})$. Hence, by using Eq. (8), one can evaluate the quantity of $\tau_{0.63 \text { (des.) } 1073 \mathrm{~K}} \approx 5 \mathrm{~min}$, which coincides (within the errors) with the similar quantity of $\tau_{0.63 \text { (des.) } 1073 \mathrm{~K}} \approx 7 \mathrm{~min}$ evaluated in the study for graphene $/ \mathrm{SiC}$ samples [17] (Item 3.6, Table 3).

A nearly complete decoration of the grain boundary network [33-42, 49] can be imagined in STM data [17]. Also, seen in STM data [17], such decoration of the nano-regions (at the grain boundaries [33-42, 49]) has a blister-like crosssection of height of about $1.7 \mathrm{~nm}$ and width of $10 \mathrm{~nm}$ order.

According to the thermodynamic analysis presented in Item 3.7, Eq. (15), such blister-like decoration nano-regions (at the grain boundaries $[33-42,49]$ ) may contain the intercalated gaseous molecular hydrogen at a high pressure. It has not been taken into account in the most related studies [17, 52-54, 57-59].

\subsection{Analysis of PES and ARPES Data on Dehydrogena- tion of Graphene/SiC Samples}

Atomic hydrogen exposures at a pressure of $P_{\mathrm{H}} \approx 1 \cdot 10^{-4}$ $\mathrm{Pa}$ and temperature $T=973 \mathrm{~K}$ on a monolayer graphene grown on the $\mathrm{SiC}(0001)$ surface are shown, to result in hy- drogen intercalation [17]. This shows that the hydrogen intercalation induces a transformation of the monolayer graphene and the carbon buffer layer to bi-layer graphene without a buffer layer. The STM, LEED, and core-level photoelectron spectroscopy (PES) measurements reveal that hydrogen atoms can go underneath the graphene and the carbon buffer layer. This transforms the buffer layer into a second graphene layer. Hydrogen exposure (15 min) results initially in the formation of bi-layer graphene (blister-like) islands with a height of $\sim 0.17 \mathrm{~nm}$ and a linear size of $\sim 20-40 \mathrm{~nm}$, covering about $40 \%$ of the sample. With larger (additional $15 \mathrm{~min}$ ) atomic hydrogen exposures, the islands grow in size and merge until the surface is fully covered with bi-layer graphene. $A(\sqrt{ } 3 \times \sqrt{ } 3) R 30^{\circ}$ periodicity is observed on the bi-layer areas. Angle resolved photoelectron spectroscopy (ARPES) and energy filtred X-ray photoelectron emission microscopy (XPEEM) investigations of the electron band structure confirm that after hydrogenation the single $\pi$-band characteristic of monolayer graphene is replaced by two $\pi$ bands that represent bi-layer graphene. Annealing an intercalated sample, representing bi-layer graphene, to a temperature of $1123 \mathrm{~K}$ or higher, re-establishes the monolayer graphene with a buffer layer on $\mathrm{SiC}(0001)$.

The dehydrogenation has been performed by subsequently annealing (for a few minutes) the hydrogenated samples at different temperatures, from 1023 to $1273 \mathrm{~K}$. After each annealing step, the depletion of hydrogen has been probed by PES and ARPES.

From the data, using Eqs. $(8,9)$, the following tentative quantities have been determined: $\tau_{0.63 \text { (des.) }}$ (at $1023 \mathrm{~K}$ and $1123 \mathrm{~K}$ ), $\Delta H_{\text {(des.) }} \approx 3.6 \mathrm{eV}$ and $K_{0 \text { (des.) }} \approx 2 \cdot 10^{14} \mathrm{~s}^{-1}$ (Table 3 ). These results can be interpreted so that the model of the interaction of hydrogen and silicon atoms at the graphene-SiC interface result in $\mathrm{Si}-\mathrm{C}$ bonds at the intercalated islands. Obviously, the quantities of $K_{0(\text { des.) }}$ and $\Delta H_{\text {(des.) }}$ correspond to those of the Polanyi-Wigner equation [14] relevant for the Si-C bonds [17].

\subsection{Analysis of TDS and STM data on HOPG treated by hydrogen}

In [15], atomic hydrogen accumulation in HOPG samples and etching their surface on hydrogen thermal desorption (TD) have been studied by using a scanning tunneling microscope (STM) and atomic force microscope (AFM). STM investigations revealed that the surface morphology of untreated reference HOPG samples was found to be atomically flat (Fig. 2 (a)), with a typical periodic structure of graphite (Fig. 2 (b)). Atomic hydrogen exposure (treatment) of the reference HOPG samples (30-125 min at atomic hydrogen pressure $P_{\mathrm{H}} \approx 10^{-4} \mathrm{~Pa}$ and a near-room temperature $\sim 300 \mathrm{~K}$ ) to different atomic hydrogen doses $(D)$, has drastically changed the initially flat HOPG surface into a rough surface, covered with nanoblisters with an average radius of $\sim 25 \mathrm{~nm}$ and an average height of $\sim 4 \mathrm{~nm}$ (Figs. 2 (c) and 2 (d)).

Thermal desorption (TD) of hydrogen has been found in heating of the HOPG samples under mass spectrometer control. As shown in Fig. (3 a), with the increase of the total hydrogen doses $(D)$ to which HOPG samples have been exposed, the desorbed hydrogen amounts $(Q)$ increase and the 
percentage of $D$ retained in samples $(Q)$ approaches towards a saturation stage. After TD, no nanoblisters were visible on the HOPG surface, the graphite surface was atomically flat, and covered with some etch-pits of nearly circular shapes, one or two layers thick (Fig. (3 b)). This implies that after release of the captured hydrogen gas, the blisters become empty of hydrogen, and the HOPG surface restores to a flat surface morphology under the action of corresponding forces.

According to [15], nanoblisters found on the HOPG surface after atomic hydrogen exposure are simply monolayer
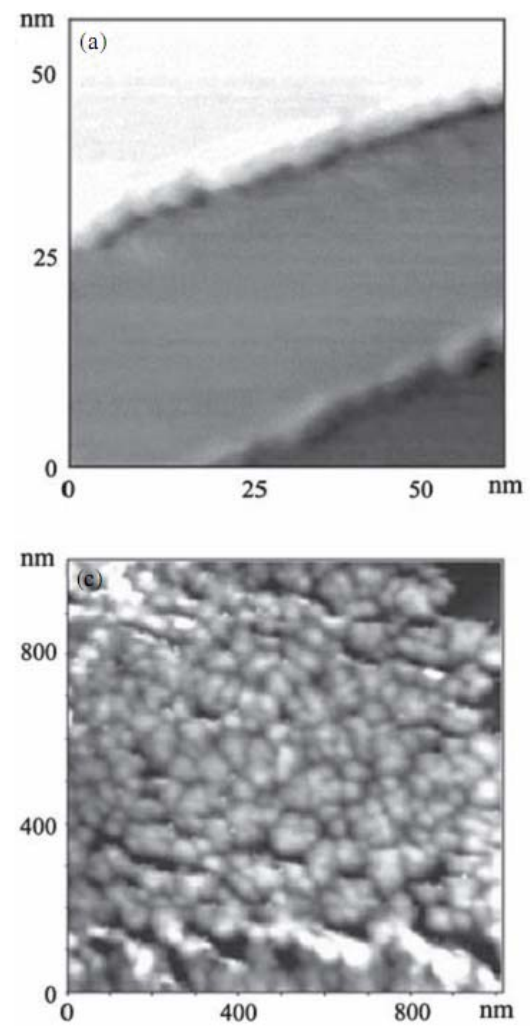

graphite (graphene) blisters, containing hydrogen gas in molecular form (Fig. 4). As suggested, atomic hydrogen intercalates between layers in the graphite net through holes in graphene hexagons, because of the small diameter of atomic hydrogen, compared to the hole's size, and is then converted to a $\mathrm{H}_{2}$ gas form which is captured inside the graphene blisters, due to the relatively large kinetic diameter of hydrogen molecules. However, such interpretation is in contradiction with that noted in Item 1 (Introduction) results [8, 32], that it is almost impossible for a hydrogen atom to pass through the six-membered ring of graphene at room temperature. It is reasonable to assume that in HOPG [15] samples atomic
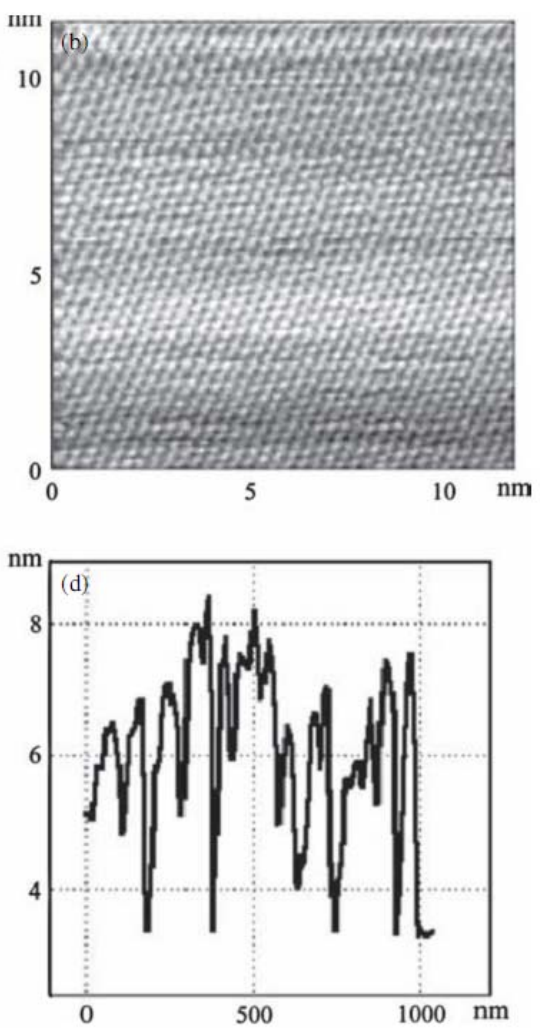

Fig. (2). STM images of the untreated HOPG sample [15] (under ambient conditions) taken from areas of (a) $60.8 \mathrm{x} 60.8 \mathrm{~nm}$ and (b) $10.9 \times 10.9 \mathrm{~nm}$ (high resolution image of the square in image (a)). (c). AFM image (area of 1x1 nm) of the HOPG sample subjected to atomic hydrogen dose $(D)$ of $1.8 \cdot 10^{16} \mathrm{H}^{0} / \mathrm{cm}^{2}$. (d) Surface height profile obtained from the AFM image reported in (c). The STM tunnel $\mathrm{V}_{\text {bias }}$ and current are 50-100 $\mathrm{mV}$ and 1-1.5 $\mathrm{mA}$, respectively.
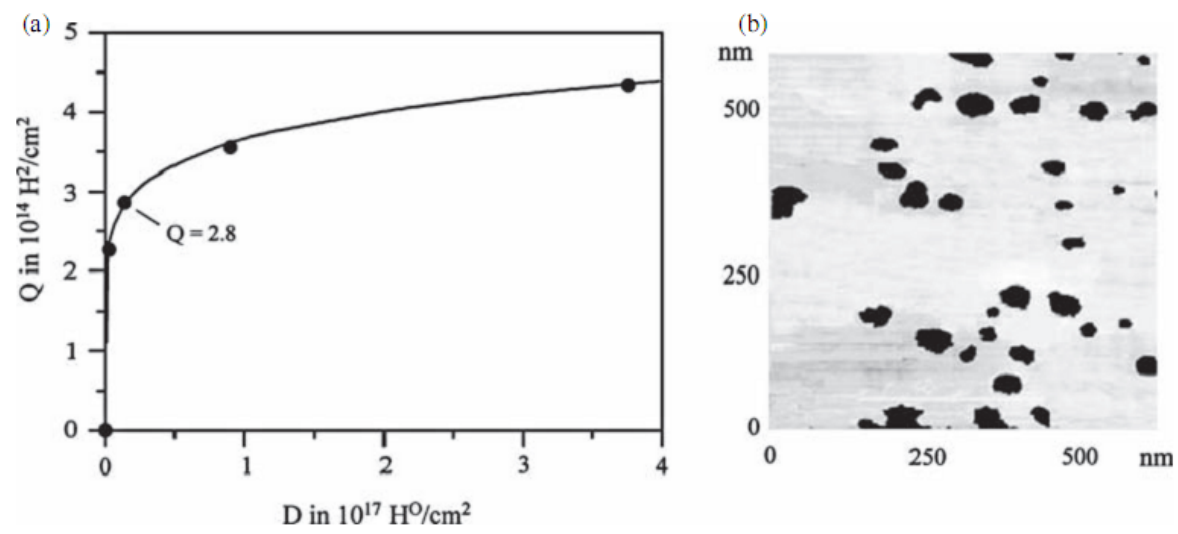

Fig. (3). (a) Hydrogen storage efficiency of HOPG samples [15], desorbed molecular hydrogen quantity $(Q)$ versus dose $(D)$ of atomic hydrogen exposure. (b) STM image for $600 \times 600 \mathrm{~nm}$ area of the HOPG sample subjected to atomic hydrogen dose of $1.8 \cdot 10^{16} \mathrm{H}^{0} / \mathrm{cm}^{2}$, followed by hydrogen thermal desorption. 


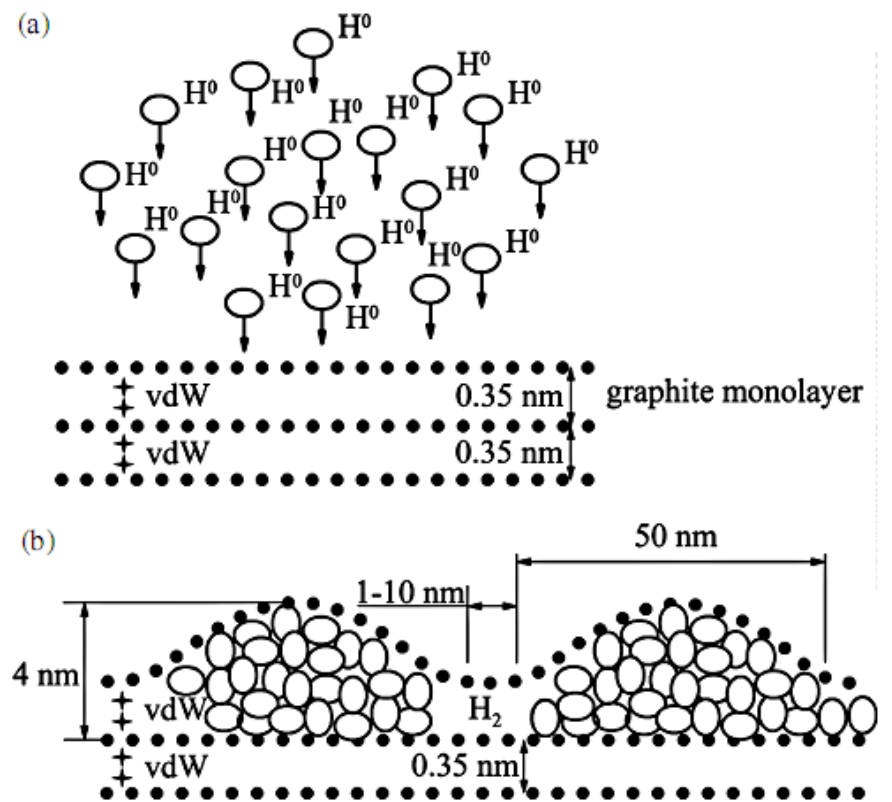

Fig. (4). Model showing the hydrogen accumulation (intercalation) in HOPG, with forming blister-like nanostructures. (a) Pre-atomic hydrogen interaction step. (b) $\mathrm{H}_{2}$, captured inside graphene blisters, after the interaction step. Sizes are not drawn exactly in scale [15].

hydrogen passes into the graphite near-surface closed nanoregions (the graphene nanoblisters) through defects (perhaps, mainly through triple junctions of the grain and/or subgrain boundary network) in the surface graphene layer. It is also expedient to note that in Fig. $(3 \mathbf{~ b})$, one can imagine some grain boundary network decorated by the etch-pits.

The average blister has a radius of $\sim 25 \mathrm{~nm}$ and a height $\sim 4 \mathrm{~nm}$. Approximating the nanoblister to be a semi-ellipse form, results in the blister area $S_{\mathrm{b}} \approx 2.0 \cdot 10^{-11} \mathrm{~cm}^{2}$ and its volume $V_{\mathrm{b}} \approx 8.4 \cdot 10^{-19} \mathrm{~cm}^{3}$. The amount of retained hydrogen in this sample becomes $Q \approx 2.8 \cdot 10^{14} \mathrm{H}_{2} / \mathrm{cm}^{2}$ and the number of hydrogen molecules captured inside the blister becomes $n \approx$ $\left(Q S_{\mathrm{b}}\right) \approx 5.5 \cdot 10^{3}[15]$. Thus, within the ideal gas approximation, and accuracy of one order of the magnitude, the internal pressure of molecular hydrogen in a single nanoblister at near-room temperature $(T \approx 300 \mathrm{~K})$ becomes $P_{\mathrm{H} 2} \approx\left\{k_{\mathrm{B}}(Q\right.$ $\left.\left.S_{\mathrm{b}}\right) T / V_{\mathrm{b}}\right\} \approx 10^{8} \mathrm{~Pa}$. The hydrogen molecular gas density in the blisters (at $T \approx 300 \mathrm{~K}$ and $P_{\mathrm{H} 2} \approx 1 \cdot 10^{8} \mathrm{~Pa}$ ) can be estimated as $\rho \approx\left\{\left(Q M_{\mathrm{H} 2} S_{\mathrm{b}}\right) / V_{\mathrm{b}}\right\} \approx 0.045 \mathrm{~g} / \mathrm{cm}^{3}$, where $M_{\mathrm{H} 2}$ is the hydrogen molecule mass. It agrees with data [60] considered in [18-21], on the hydrogen (protium) isotherm of 300 $\mathrm{K}$.

These results can be quantitatively described, with an accuracy of one order of magnitude, with the thermodynamic approach $[44,46]$, by using the condition of the thermoelastic equilibrium for the reaction $\left(2 \mathrm{H}_{\text {(gas) }} \rightarrow \mathrm{H}_{2 \text { (gas_in_blisters) }}\right)$ of intercalation of atomic gas hydrogen $\left(\mathrm{H}_{(\mathrm{gas})}\right)$ of low pressure $\left(P_{\mathrm{H}}\right)$ to the graphene blisters, resulting in transformation of the atomic hydrogen to molecular gas $\left(\mathrm{H}_{2 \text { (gas_in blisters) }}\right)$ of a high pressure $\left(P_{\mathrm{H} 2}\right)$ inside the blisters, as follows [18]:

$\left(P_{\mathrm{H} 2} / P_{\mathrm{H} 2}^{0}\right) \approx\left(P_{\mathrm{H}} / P_{\mathrm{H}}^{0}\right)^{2} \exp \left\{\left[\Delta H_{\mathrm{dis}}-T \Delta S_{\mathrm{dis}}-P_{\mathrm{H} 2}^{*} \Delta V\right)\right] / k_{\mathrm{B}}$ $T\}$

where $P^{*}{ }_{\mathrm{H} 2} \approx P_{\mathrm{H} 2} \approx 1 \cdot 10^{8} \mathrm{~Pa}$ is related to the blister "wall" back pressure (caused by $P_{\mathrm{H} 2}$ ) - the so called surface pressure [44], $P_{\mathrm{H}} \approx 1 \cdot 10^{-4} \mathrm{~Pa}$ is the atomic hydrogen pressure corre- sponding to the atomic flux [15], $P_{\mathrm{H} 2}^{0}=P_{\mathrm{H}}^{0}=1 \mathrm{~Pa}$ are the standard pressures [44, 46], $\Delta H_{\mathrm{dis}}=4.64 \mathrm{eV}$ is the experimental value [45] of the dissociation energy (enthalpy) of one molecule of gaseous hydrogen (at room temperatures), $\Delta S_{\text {dis }}=11.8 k_{\mathrm{B}}$ is the dissociation entropy [45], $\Delta V \approx\left(S_{\mathrm{b}} r_{\mathrm{b}} /\right.$ $n$ ) is the apparent volume change, $r_{\mathrm{b}} \approx 30 \mathrm{~nm}$ is the radius of curvature of nanoblisters (at the nanoblister edge, Fig. (4 b)), $N_{\mathrm{A}}$ is the Avogadro number, and $T \approx 300 \mathrm{~K}$. The quantity of $\left(P^{*}{ }_{\mathrm{H} 2} \Delta V\right)$ is related to the work of the nanoblister surface increasing with an intercalation of 1 molecule of $\mathrm{H}_{2}$.

The value of the tensile stresses $\sigma_{\mathrm{b}}$ (caused by $P^{*}{ }_{\mathrm{H} 2}$ ) in the graphene nanoblister "walls" with a thickness of $d_{\mathrm{b}}$ and a radius of curvature $r_{\mathrm{b}}$ can be evaluated from another condition (equation) of the thermo-elastic equilibrium of the system in question, which is related to Eq. (15), as follows [44, 18]:

$\sigma_{\mathrm{b}} \approx\left(P^{*}{ }_{\mathrm{H} 2} r_{\mathrm{b}} / 2 d_{\mathrm{b}}\right) \approx\left(\varepsilon_{\mathrm{b}} E_{\mathrm{b}}\right)$.

where $\varepsilon_{\mathrm{b}}$ is a degree of elastic deformation of the graphene nanoblister walls, and $E_{\mathrm{b}}$ is the Young's modulus of the graphene nanoblister walls. Substituting the quantities of $P^{*} \mathrm{H} 2 \approx$ $1 \cdot 10^{8} \mathrm{~Pa}, r_{\mathrm{b}} \approx 30 \mathrm{~nm}$ and $d_{\mathrm{b}} \approx 0.15 \mathrm{~nm}$ in the first part of Eq. (16) results in the value of $\sigma_{\mathrm{b}} \approx 1 \cdot 10^{10} \mathrm{~Pa}$.

The degree of elastic deformation of the graphene nanoblister walls, apparently reaches $\varepsilon_{\mathrm{b}[15]} \approx 0.1$. Hence, with Hooke's law of approximation, using the second part of Eq. (16), one can estimate, with the accuracy of one-two orders of the magnitude, the value of the Young's modulus of the graphene nanoblister walls: $E_{\mathrm{b}} \approx\left(\sigma_{\mathrm{b}} / \varepsilon_{\mathrm{b}}\right) \approx 0.1 \mathrm{TPa}$. It is close (within the errors) to the experimental value [48] of the Young's modulus of graphene $\left(E_{\text {graphene }}=1.0 \mathrm{TPa}\right)$. Therefore, it is consistent with the results of analysis in the experimental value of the degree of elastic deformation $\left(\varepsilon_{\text {fix.membr. }} \approx 0.1\right)$ of the hydrogenated fixed graphene membranes, and the assumed stretching stress value $\left(\sigma_{\text {fix.membr. }} \approx\right.$ 
$\left.\left(\varepsilon_{\text {fix.membr. }} E_{\text {graphene }}\right) \approx 0.1 \mathrm{TPa}\right)$ in the expanded regions (domains or grains) of the material [5].

The experimental data $[15,59]$ on the thermal desorption of hydrogen from graphene nanoblisters in pyrolytic graphite can be approximated by three thermodesorption (TDS) peaks, i.e., \# I [59] with $T_{\max \# \mathrm{I}} \approx 1123 \mathrm{~K}$, \# II [59] with $T_{\text {max\#II }}$ $\approx 1523 \mathrm{~K}$, and \# III [59] with $T_{\max \# I I I} \approx 1273 \mathrm{~K}$. But their treatment, with using the above mentioned methods [14], is difficult due to some uncertainty relating to the zero level of the desorption flux quantity. Nevertheless, TDS peak \# I can be characterized by the activation desorption energy $\Delta H_{\text {(des.)\#I }}$ $=2.4 \pm 0.5 \mathrm{eV}$, and by the per-exponential factor of the reaction rate constant of $K_{0 \text { (des.)\#I }} \approx 2 \cdot 10^{10} \mathrm{~s}^{-1}$ (Table 3). Analyses have shown that TDS peak I is related to TDS peak (process) III in [14, 18-21], for which the apparent diffusion activation energy is $Q_{\text {app.III }}=(2.6 \pm 0.3) \mathrm{eV}$ and $D_{0 \text { app.III }} \approx 3 \cdot 10^{-3} \mathrm{~cm}^{2} / \mathrm{s}$. Hence, one can obtain (with accuracy of one-two orders of the magnitude) a reasonable value of the diffusion character- istic size of $L_{\text {TDS-peak\#I }} \approx\left(D_{0 \text { app.III }} / K_{0 \text { (des. }) \text { II }}\right)^{1 / 2} \approx 4 \mathrm{~nm}$, which is related to the separating distance between the graphene nanoblisters or (within the errors) to the separation distance between etch-pits (Fig. 3(b)) in the HOPG specimens [15, 59]. Thus, TDS peak (process) $I$ is related to TDS peak (process) III in [14, 18-21], which is related to model " $\mathrm{F}^{*}$ " (Fig. 1) considered in Item 2.4. Model " $\mathrm{F}^{*}$ " is characterized by the quantity $\Delta H_{(\mathrm{C}-\mathrm{H}) \text { "F*" }}=(2.5 \pm 0.3) \mathrm{eV}\left(\approx Q_{\text {app.III }}\right)$ that coincides with the similar quantities for graphanes (Table 1).

Finally, it is reasonable to assume that the inner surfaces "walls" in the graphene nanoblisters in HOPG are hydrogenated, and that the graphene "walls" situation is related to some hydrogenated graphenes (Table 1). Obviously, such hydrogenation of the inner graphene surfaces in the nanoblisters occurs under action of the gaseous molecular hydrogen of a high pressure $\left(P_{\mathrm{H} 2}\right)$ intercalated into the stressed (expanded) hydrogenated graphene nanoblister "walls" possessing of a high Young's modulus $[15,59]$.

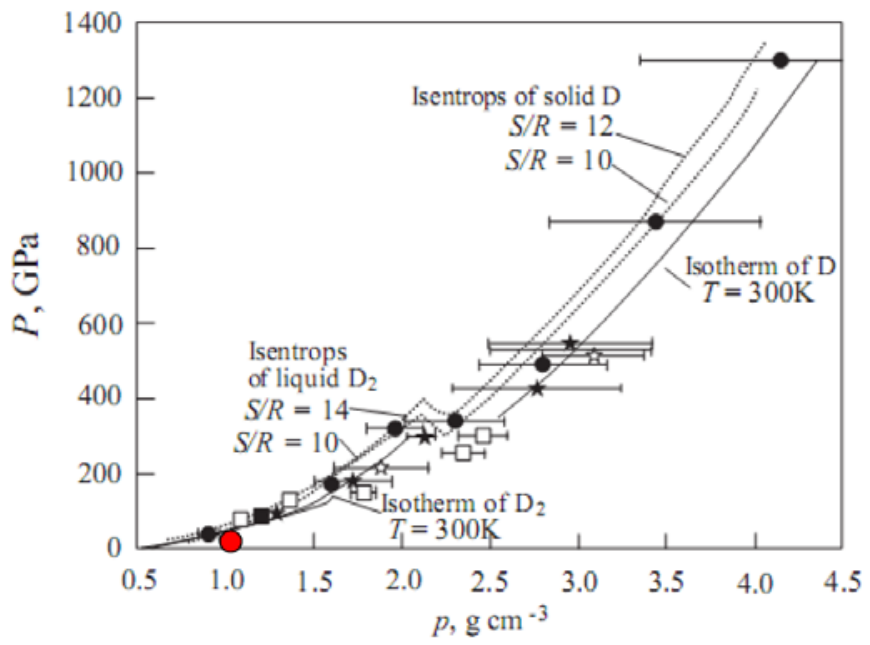

Fig. (5). Isentropes (at entropies $S / R=10,12$ and 14, in units of the gas constant $R$ ) and isotherms (at $T=300 \mathrm{~K}$ ) of molecular and atomic deuterium [60]. The symbols show the experimental data, and curves fit calculated dependences. The density $(\rho)$ of protium was increased by a factor of two (for the scale reasons). Thickened portion of the curve is an experimental isotherm of solid form of molecular hydrogen $\left(\mathrm{H}_{2}\right)$. The additional red circle corresponds to a value of the twinned density $\rho \approx 1 \mathrm{~g} / \mathrm{cm}^{3}$ of solid $\mathrm{H}_{2}$ (at $T \approx 300 \mathrm{~K}$ ) and a near-megabar value of the external compression pressure $P \approx 50 \mathrm{GPa}[18]$.

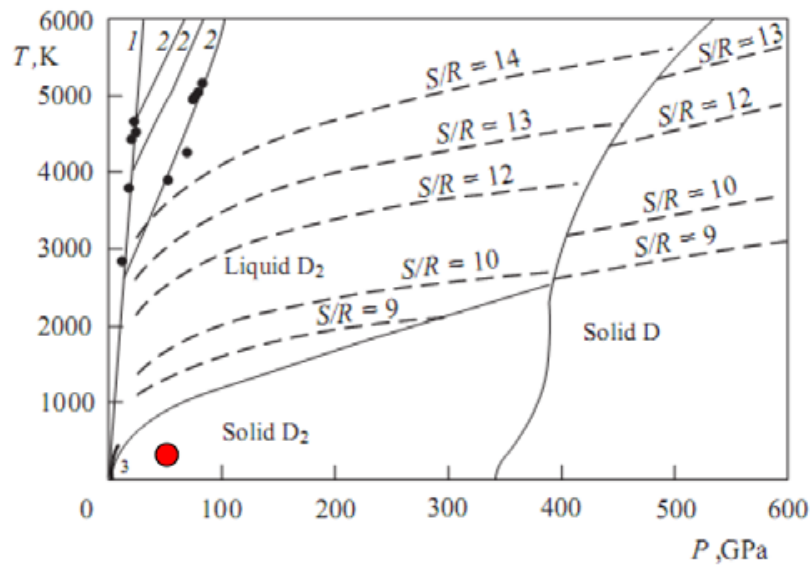

Fig. (6). Phase diagram, adiabats, and isentropes of deuterium calculated with the equation of state: 1 and 2 are a single and a doubled adiabat, $\bullet$ - the experimental data, 3 - melting curve, thickened portion of the curve - the experimental data. The additional red circle corresponds to a value of temperature $T \approx 300 \mathrm{~K}$ and a near-megabar value of the external compression pressure $P \approx 50 \mathrm{GPa}$ [18,60]. 
As considered in the next Section, a similar (to some extent) situation may occur in hydrogenated graphite nanfibers (GNFs).

\section{A POSSIBILITY OF INTERCALATION OF SOLID $\mathrm{H}_{2}$ INTO HYDROGENATED GRAPHITE NANOFI- BERS, RELEVANCE TO THE HYDROGEN ON- BOARD STORAGE PROBLEM}

The possibility of intercalation of solid $\mathrm{H}_{2}$ into hydrogenated graphite nanofibers (considered in [18-21]) is based on the following facts:

1). According to the data from Figs. (5 and 6) (from [60]), a solid molecular hydrogen (or deuterium) of density of $\rho_{\mathrm{H} 2}=0.3-0.5 \mathrm{~g} / \mathrm{cm}^{3}\left(\mathrm{H}_{2}\right)$ can exist at $300 \mathrm{~K}$, and an external pressure of $P=30-50 \mathrm{GPa}$.

2). As followed from the above presented results of analysis of data [15, 59] (Figs. 2-4) and Eqs. (15) and (16), the external surface pressure of $P=P^{*}{ }_{\mathrm{H} 2}=30$ $50 \mathrm{GPa}$ at $T \approx 300 \mathrm{~K}$ may be provided, at the expense of the free association energy of atomic hydrogen $\left(T \Delta S_{\text {dis }}-\Delta H_{\text {dis }}\right)$, inside some closed hydrogenated (in gaseous atomic hydrogen with the corresponding pressure $P_{\mathrm{H}}$ ) graphene nanostructures possessing of a high Young's modulus ( $E \leq 1 \mathrm{TPa})$.

3). As shown in [18], the treatment of the data (Fig. 7) on hydrogenation of graphite nanofibers (GNFs) resulted in the experimental value of the hydrogen density $\rho_{\mathrm{H} 2}$ $=(0.5 \pm 0.2) \mathrm{g}\left(\mathrm{H}_{2}\right) / \mathrm{cm}^{3}\left(\mathrm{H}_{2}\right)$ (or $\rho_{\text {(H2-C-system) }} \approx 0.2$ $\mathrm{g}\left(\mathrm{H}_{2}\right) / \mathrm{cm}^{3}\left(\mathrm{H}_{2}\right.$-C-system $\left.)\right)$ of the intercalated highpurity reversible hydrogen $\left(\sim 17\right.$ mass.\% $\left.\mathrm{H}_{2}\right)$ corresponding to the state of solid molecular hydrogen at a surface pressure of $P=P^{*}{ }_{\mathrm{H} 2} \approx 50 \mathrm{GPa}$ and $T \approx 300 \mathrm{~K}$, according to data from Figs. (5) and (6) [60-62].

4). Substituting in Eq. (16) the quantities of $P^{*}{ }_{\mathrm{H} 2} \approx P_{\mathrm{H} 2} \approx$ $5 \cdot 10^{10} \mathrm{~Pa}, \varepsilon_{\mathrm{b}} \approx 0.1$ (Fig. 7), the largest possible Young's modulus value [48] of $E_{\mathrm{b}} \approx 10^{12} \mathrm{~Pa}$, the largest possible value of the tensile stresses $\left(\sigma_{\mathrm{b}} \approx 10^{11} \mathrm{~Pa}\right)$ in the edge graphene "walls" (of a thickness of $d_{\mathrm{b}}$ and a radius of curvature of $r_{\mathrm{b}}$ ) of the slit-like closed nanopores of the lens shape, one can obtain the quantity of $\left(r_{\mathrm{b}} / d_{\mathrm{b}}\right) \approx 4$. It is reasonable to assume $r_{\mathrm{b}} \approx 20$ $\mathrm{nm}$; hence, a reasonable value follows of $d_{\mathrm{b}} \approx 5 \mathrm{~nm}$ (Fig. 7). A similar result can be obtained, supposing the quantity of $E_{\mathrm{b}} \approx 10^{11} \mathrm{~Pa}$ (as it is for the hydrogenated graphene nanoblisters in HOPG, Item 3.7) [15].

5). As noted in [18-21], a definite residual plastic deformation of the hydrogenated graphite nano-regions is observed in Fig. (7). Such plastic deformation of the nanoregins during hydrogenation of GNFs, may be accompanied with some mass transfer resulting in such thickness $\left(d_{\mathrm{b}[61]}\right)$ of the walls in [61].

6). As shown in [18-21], a very important role of the spillover effect [63-69] is the relevance to hydrogenation of GNFs [61, 62].

7). The related data presented in [70-73], and allow us reasonably to assume a break-through character of results [18-21], relevant for solving of the current prob-

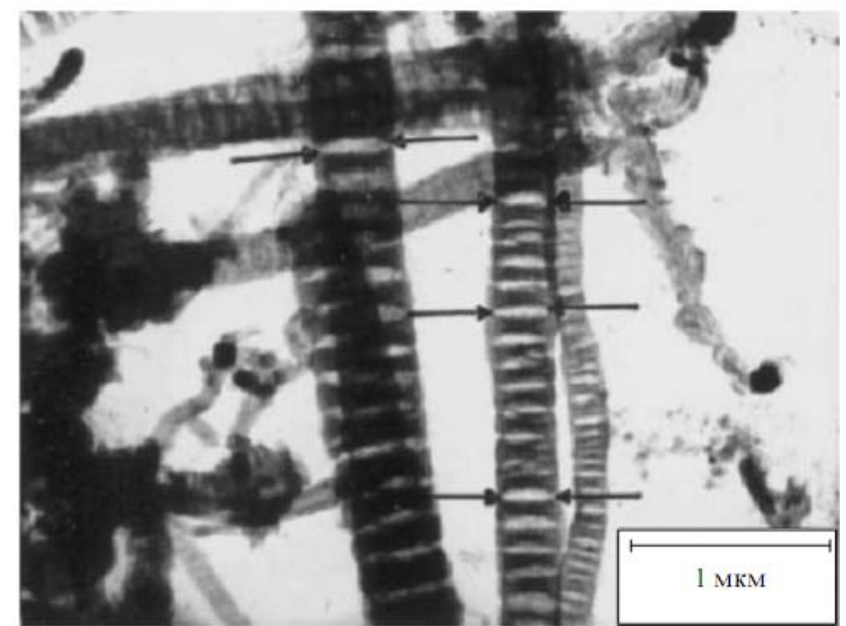

Fig. (7). Micrographs of hydrogenated graphite nanofibers (GNFs) after release from them (at $\sim 300 \mathrm{~K}$ for $\sim 10 \mathrm{~min}$ ) of intercalated (obviously, reversible) high-purity hydrogen ( 17 mass.\% - the gravimetrical reversible hydrogen capacity). It occurs under a sharp decrease of the external (locking-like) pressure of $\mathrm{H}_{2}$ (from $\sim 10$ $\mathrm{MPa}$ to $\sim 1 \mathrm{MPa}$, at $\sim 300 \mathrm{~K})[61,62]$. The arrows in the picture indicate some of the slit-like closed nanopores of the lens shape (between hydrogenated graphite nano-regions), where the intercalated reversible high-purity hydrogen was localized. Dehydrogenation of the hydrogenated graphite nano-regions, relevance to the covalent bonded "non-reversible" hydrogen in them, occurs during thermodesorption annealing at elevated temperatures. Two TDS peaks (I, II) were observed; peak I [61,62] is related to TDS peak III in [14,18-21], (Table 3). It allows us to realize a multi-cycle process of charging-discharging of the same samples, relevance to the intercalated reversible hydrogen, with the permanently hydrogenated graphite (graphene) nanoregions.

lem $[74,75]$ of the hydrogen on-board storage in fuel cell powered vehicles.

\section{CONCLUSIONS}

1. Consideration of some of the most cited works [3-9, $17,25,51-59,62]$ and the least non-cited works [18$21,61]$ on the thermodynamic stability of a number of hydrogenated graphene layers systems (Tables 1-3) has shown expediency of further related (mainly experimental) studies for the determination of a complete and compatible set of thermodynamic characteristics of such systems.

2. It confirms the validility of the alternative view point of authors that their experimental graphane (a freestanding membrane) may have a more complex hydrogen bonding than the one suggested by theory [3], and that their epitaxial graphane may be a different material, rather than the theoretical graphane $[3,5]$.

3. Show a thermodynamic probability of existence of hydrogenated graphenes - graphanes* [18-21] possessing of a considerably higher binding (cohesive) energy, in comparison with the theoretical graphanes $[3,25]$.

4. It has been reasonably assumed [70-73] and (Figs. 8 and 9) a break-through character of analytical results 


\section{Mass and Volume Densities}

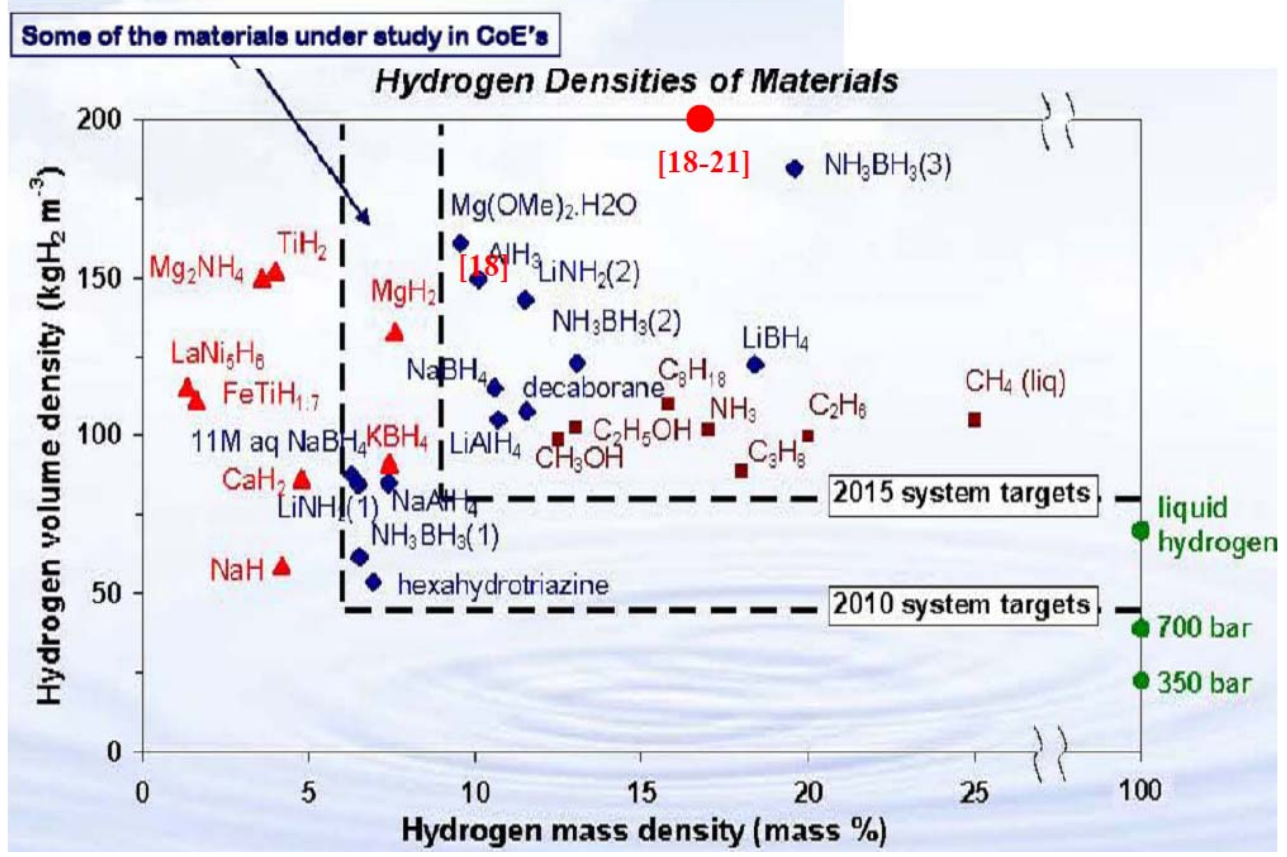

Fig. (8). It is shown [71] (in the face of known achievements) U.S. DOE targets [74], relevant to gravimetric and volumetric hydrogen onboard storage densities for $2010\left(6.0\right.$ mass. $\% \mathrm{H}_{2}, 45 \mathrm{~kg}\left(\mathrm{H}_{2}\right) / \mathrm{m}^{3}$ (system)) and for $2015\left(9.0\right.$ mass.\% $\left.\mathrm{H}_{2}, 81 \mathrm{~kg}\left(\mathrm{H}_{2}\right) / \mathrm{m}^{3}(\mathrm{system})\right)$. The additional red circle is related to the solid hydrogen intercalated into the hydrogenated graphite nanofibers (GNFs) [18-21].

\section{ENERGY CARRIERS}

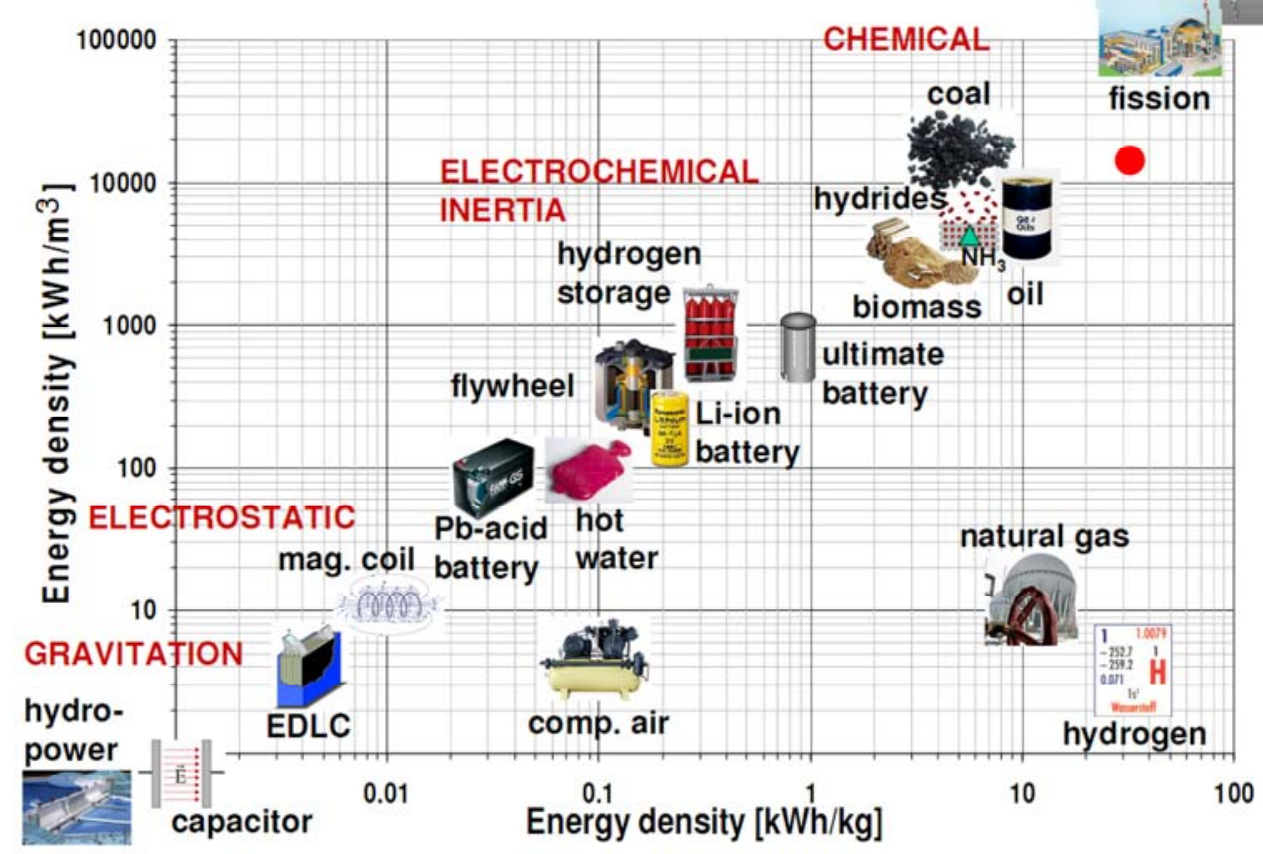

Fig. (9). Shown the known data on volumetric and gravimetric energy densities for different energy carriers [70]. The additional symbol is related to the solid hydrogen intercalated into the hydrogenated GNFs [18-21].

[18-21] on the solid hydrogen intercalated in hydrogenated graphite nanofibers (Fig. 7), relevant for solving the current problem $[74,75]$ of hydrogen onboard storage in fuel cell powered vehicles.
5. A constructive open discussion and, may be, a related International project and/or cooperation on the above considered thermodynamic aspects of the hydrogenated graphene layer systems seems expedient, rele- 
vant to the promotion of further developments, particularly in the developing of basic grounds in thediscussion of a possible break-through in nanotechnology for hydrogen on-board storage [18-21].

STM
STS
LEED
HREELS

TDS

TPD

TD

PES

ARPES

XPEEM

TEM

AFM

HOPG

SWCNTs

GNFs

SSHG

$E_{\mathrm{g}}$

$\Delta H_{\text {bind.(graphane) }}$

$\Delta H_{\mathrm{f} 298(\text { graphane })}^{0}=\Delta H_{1} \quad=$

the standard energy of formation of the compounds $\quad\left(\mathrm{CH}_{\text {(graphane) }}\right)$ from crystalline graphite and gaseous molecular hydrogen at the standard pressure and temperature conditions

$\Delta H_{(\mathrm{C}-\mathrm{H}) \text { graphane }}=-\Delta H_{2} \quad=\quad$ the break-down energy of C-H $s p^{3}$ bond in graphane, relevant to the breaking away of one hydrogen atom from the material

$\Delta H_{\text {cohes.(graphene) }}=$ the cohesive (binding) energy for graphene, which characterizes the break-down energy of $1.5 \mathrm{C}-\mathrm{C} s p^{2}$ bond in graphene, and which is relevant to the breaking away of one carbon atom from the material

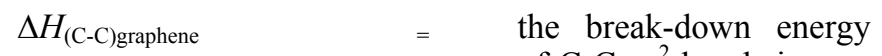
of C-C $s p^{2}$ bonds in graphene

$\Delta H_{(\mathrm{C}-\mathrm{C}) \text { graphite }} \approx \Delta H_{(\mathrm{C}-\mathrm{C}) \text { graphene }}=$ the break-down energy of $\mathrm{C}-\mathrm{C} s p^{2}$ bonds in graphite

$\Delta H_{(\mathrm{C}-\mathrm{C}) \text { diamond }}=$ the break-down energy of C-C $s p^{3}$ bonds in diamond

$\Delta H_{\text {subl.(diamond) }}=\quad$ the diamond sublimation energy

$\Delta H_{\text {subl.(graphite) }}=$ the graphite sublimation energy;

$\tau_{0.63}=(1 / K) \quad=\quad$ the time of the removal of $\sim 63 \%$ of the initial hydrogen concentration $\mathrm{C}_{0}$ (i.e., $-\Delta C / C_{0} \approx 0.63$ ), $K$ being the desorption rate constant

\begin{tabular}{|c|c|c|}
\hline$\Delta H_{\mathrm{des}}$ & $=$ & $\begin{array}{l}\text { the desorption activation } \\
\text { energy }\end{array}$ \\
\hline$K_{0}$ & $=$ & $\begin{array}{l}\text { the per-exponential (or } \\
\text { frequency) factor of the } \\
\text { reaction rate constant } \\
(K) \text {. }\end{array}$ \\
\hline
\end{tabular}

\section{ACKNOWLEDGMENTS}

The author is grateful to H.G. Xiang, M.-H. Whangbo, D.C. Elias, C. Casiraghi, A. Eckmann, N. Tombros, B.J. Van Wees, A. Castellanos-Gomez, R. Bisson, T. Yu, L. Hornekaer and Z. Waqar for helpful discussions, valuable completing and/or reading of the related parts of the present analytical results.

\section{REFERENCES}

[1] Geim, A.K.; Novoselov, K.S. The rise of graphene. Nat. Mater., 2007, 6 (3), 183-191.

[2] Palerno, V. Not a molecule, not a polymer, not a substrate...the many faces of graphene as a chemical platform. Chem. Commun, 2013, 49 (28), 2848-2857.

[3] Sofo, J.O.; Chaudhari, A.S.; Barber G.D. Graphane: A twodimensional hydrocarbon. Phys. Rev. B, 2007, 75, 153401-1-4.

[4] Openov, L.A.; Podlivaev, A.I. Thermal desorption of hydrogen from graphane. Tech. Phys. Lett., 2010, 36 (1), 31-33. 
[5] Elias, D.C.; Nair, R.R.; Mohiuddin, T.M.G.; Morozov, S.V.; Blake, P.; Halsall, M.P.; Ferrari, A.C.; Boukhvalov, D.W.; Katsnelson, M.I.; Geim, A.K.; Novoselov, K.S. Control of graphene's properties by reversible hydrogenation: evidence for graphane. Science., 2009, 323 (5914), 610-626.

[6] Openov, L.A.; Podlivaev, A.I. Thermal stability of single-side hydrogenated graphene. Tech. Phys., 2012, 57 (11), 1603-1605.

[7] Pujari, B.S.; Gusarov, S.; Brett, M.; Kovalenko, A. Single-sidehydrogenated graphene: Density functional theory predictions. Phys. Rev. B., 2011, 84, 041402-1-6.

[8] Xiang, H.J.; Kan, E.J.; Wei, S.-H.; Gong, X.G.; Whangbo, M.-H. Thermodynamically stable single-side hydrogenated graphene. Phys. Rev. B., 2010, 82, 165425-1-4.

[9] Podlivaev, A.I.; Openov, L.A. On thermal stability of graphone. Semiconductors, 2011, 45 (7), 958-961.

[10] Nikitin, A.; Li, X.; Zhang, Z.; Ogasawara, H.; Dai, H.; Nilsson, A. Hydrogen storage in carbon nanotubes through the formation of stable C-H bonds. Nano Lett., 2008, 8 (1), 162-167.

[11] Nikitin, A.; Näslund, L.-A.; Zhang, Z.; Nilsson, A. C-H bond formation at the graphite surface studied with core level spectroscopy. Surf, Sci., 2008, 602 (14), 2575-2580.

[12] Bauschlicher, C.W. (Jr.); So, C.R. High coverages of hydrogen on (10.0), (9.0) and (5.5) carbon nanotubes. Nano Lett., 2002, 2 (4), 337-341.

[13] Pimenova, S.M.; Melkhanova, S.V.; Kolesov, V.P.; Lobach, A.S. The enthalpy of formation and $\mathrm{C}-\mathrm{H}$ bond enthalpy hydrofullerene $\mathrm{C}_{60} \mathrm{H}_{36}$. J. Phys. Chem. B., 2002, 106 (9), 2127-2130.

[14] Nechaev, Yu. S. Carbon nanomaterials, relevance to the hydrogen storage problem. J. Nano Res., 2010, 12, 1-44.

[15] Waqar, Z. Hydrogen accumulation in graphite and etching of graphite on hydrogen desorption. J. Mater. Sci., 2007, 42 (4), 11691176.

[16] Nechaev, Yu.S.; Alexeeva, O.K.; Oechsner, A. Analytical review on the hydrogen multilayer intercalation in carbonaceous nanostructures: Relevance for development of super-adsorbents for fuelcell-powered vehicles. J. Nanosci. Nanotechnol., 2009, 9 (6), 39493958.

[17] Watcharinyanon, S.; Virojanadara, C.; Osiecki, J.R.; Zakharov, A.A.; Yakimova, R.; Uhrberg, R.I.G.; Johansson, L.I. Hydrogen intercalation of graphene grown on $6 \mathrm{H}-\mathrm{SiC}(0001)$. Surf. Sci., 2011, 605 (17-18), 1662-1668.

[18] Nechaev, Yu.S. Solid hydrogen in multigraphane nanostructures. Int. Sc; J. Fundament. Appl. Phys., 2012, 1, 38-60 (in Russian).

[19] Nechaev, Yu.S. On the solid hydrogen intercalation in multilayer graphane-like nanostructures, relevance to the storage applications. J. Nano Res., 2011, 15, 75-93.

[20] Nechaev, Yu.S. On the solid hydrogen carrier intercalation in graphane-like regions in carbon-based nanostructures. Int. J. Hydro. Ener., 2011, 36, 9023-9031.

[21] Nechaev, Yu.S. The high-density hydrogen carrier intercalation in graphane-like nanostructures, relevance to its on-board storage in fuel-cell-powered vehicles. Open Fuel Cell J., 2011, 4, 16-29.

[22] Xiang, H.; Kan, E.; Wei, S.-H.; Whangbo, M.-H.; Yang J. "Narrow" graphene nanoribbons made easier by partial hydrogenation. Nano Lett., 2009, 9 (12), 4025-4030.

[23] Lebegue, S.; Klintenberg, M.; Eriksson, O.; Katsnelson, M.I. Accurate electronic band gap of pure and functionalized graphane from GW calculations. Phys. Rev. B - Condens. Matter. Mater. Phys., 2009, 79 (24), article \# 245117.

[24] Zhou, J.; Wang, Q.; Sun, Q.; Chen, X.S.; Kawazoe, Y.; Jena, P. Ferromagnetism in semihydrogenated graphene sheet. Nano Lett., 2009, 9 (11), 3867-3870.

[25] Dzhurakhalov, A.A.; Peeters, F.M. Structure and energetics of hydrogen chemisorbed on a single graphene layer to produce graphane. Carbon, 2011, 49, 3258-3266.

[26] Ruffieux, P.; Gröning, O.; Bielmann, M.; Mauron, P.; Schlapbach, L.; Gröning, P. Hydrogen adsorption on $\mathrm{sp}^{2}$-bonded carbon: influence of the local curvature. Phys. Rev. B., 2002, 66, 245416-1-8.

[27] Sha, X.; Jackson, B. First-principles study of the structural and energetic properties of H atoms on graphite (0001) surface. Surf. Sci., 2002, 496, 318-330.

[28] Sluiter, M.H.F.; Kawazoe, Y. Cluster expansion method for adsorption: application to hydrogen chemisorption on graphene. Phys. Rev. B., 2003, 68, 085410-1-7.

[29] Yazyev, O.V.; Helm, L. Defect-induced magnetism in graphene. Phys. Rev. B, 2007, 75, 125408-1-5.
[30] Lehtinen, P.O.; Foster, A.S.; Ma, Y.; Krasheninnikov, A.V.; Nieminen, R.M. Irradiation-induced magnetism in graphite: a density functional study. Phys. Rev. Lett., 2004, 93, 187202-1-4.

[31] Boukhvalov, D.W.; Katsnelson, M.I.; Lichtenstein, A.I. Hydrogen on graphene: total energy, structural distortions and magnetism from first-principles calculations. Phys. Rev. B, 2008, 77, 035427$1-7$.

[32] Jiang, D.; Cooper, V.R.; Dai, S. Porous graphene as the ultimate membrane for gas separation. Nano Lett., 2009, 9, 4019-4024.

[33] Brito, W.H.; Kagimura, R.; Miwa, R.H. Hydrogenated grain boundaries in graphene. Appl. Phys. Lett., 2011, 98 (21), article no. 213107.

[34] Tapasztó, L.; Nemes-Incze, P.; Dobrik, G.; Jae-Yoo, K.; Hwang, C.; Biró, L.P. Mapping the electronic properties of individual graphene grain boundaries. Appl. Phys. Lett., 2012, 100 (5), article \# 05311

[35] Banhart, F.; Kotakoski, J. ; Krasheninnikov, A.V. Structural defects in graphene ( Review ). ACS Nano, 2011, 5 (1), 26-41.

[36] Yazyev, O.V.; Louie, S.G. Topological defects in graphene: Dislocations and grain boundaries. Phys. Rev. B - Condens. Matter. Mater. Phys., 2010, 81 (19), article no. 195420.

[37] Kim, K.; Lee, Z.; Regan, W.; Kisielowski, C.; Crommie, M.F.; Zettl, A. Grain boundary mapping in polycrystalline graphene. ACS Nano, 2011, 5 (3), 2142-2146.

[38] Koepke, J.C.; Wood, J.D.; Estrada, D.; Ong, Z.-Y.; He, K.T.; Pop, E.; Lyding, J.W. Atomic-scale evidence for potential barriers and strong carrier scattering at graphene grain boundaries: A scanning tunneling microscopy study. ACS Nano, 2013, 7 (1), 75-86.

[39] Zhang, J.; Zhao, J. Structures and electronic properties of symmetric and nonsymmetric graphene grain boundaries. Carbon, 2013 $55,151-159$

[40] Yakobson, B.I.; Ding, F. Observational geology of graphene, at the nanoscale ( Review). ACS Nano, 2011, 5 (3), 1569-1574.

[41] Cockayne, E.; Rutter, G.M.; Guisinger, N.P.; Crain, J.N.; First, P.N.; Stroscio, J.A. Grain boundary loops in graphene. Phys. Rev. B - Condens. Matter. Mater. Phys., 2011, 83 (19), article \# 195425.

[42] Zhang, J.; Zhao, J.; Lu, J. Intrinsic strength and failure behaviours of graphene grain boundaries. ACS Nano, 2012, 6 (3), 2704-2711.

[43] Sessi, P.; Guest, J.R.; Bode, M.; Guisinger, N.P. Patterning graphene at the nanometer scale via hydrogen desorption. Nano Lett., 2009, 9 (12), 4343-4347.

[44] Bazarov, I.P. Thermodynamics. Vysshaya Shkola, Moscow, 1976

[45] Karapet'yants, M.K.; Karapet'yants, M.L. Osnovnye Termodinamicheskie Konstanty Neorganicheskikh i Organicheskikh Veshchestv (Fundamental Thermodynamic Constants of Inorganic and Organic Substances), Khimiya, Moscow, 1968.

[46] Zhukhovitskii, A.A.; Shvartsman, L.A. Physical Chemistry. Moscow: Metallurgiya, 1987.

[47] Xie, L.; Wang, X.; Lu, J.; Ni, Z.; Luo, Z.; Mao, H.; Wang, R.; Wang, Y.; Huang, H.; Qi, D.; Liu, R.; Yu, T.; Shen, Z.; Wu, T.; Peng, H.; Özyilmaz, B.; Loh, K.; Wee, A.T.S.; Ariando; Chen, $\mathrm{W}$. Room temperature ferromagnetism in partially hydrogenated epitaxial graphene. Appl. Phys. Lett., 2011, 98 (19), article \# 193113.

[48] Lee, C.; Wei, X.; Kysar, J.W.; Hone, J. Measurement of the elastic properties and intrinsic strength of monolayer graphene. Sci., 2008 321 (5887), 385-388

[49] Eckmann, A.; Felten, A.; Mishchenko, A.; Britnell, L.; Krupke, R.; Novoselov, K.S.; Casiraghi, C. Probing the nature of defects in graphene by Raman spectroscopy. Nano Lett., 2012, 12 (8), 39253930.

[50] Yang, F.H.; Yang, R.T. Ab initio molecular orbital study of adsorption of atomic hydrogen on graphite: Insight into hydrogen storage in carbon nanotubes. Carbon, 2002, 40, 437-444.

[51] Wojtaszek, M.; Tombros, N.; Garreta, A.; Van Loosdrecht, P.H.M.; Van Wees, B.J. A road to hydrogenating graphene by a reactive ion etching plasma. J. Appl. Phys., 2011, 110 (6), article \# 063715 .

[52] Castellanos-Gomez, A.; Wojtaszek, M.; Arramel; Tombros, N.; Van Wees, B.J. Reversible hydrogenation and bandgap opening of graphene and graphite surfaces probed by scanning tunneling spectroscopy. Small, 2012, 8 (10), 1607-1613.

[53] Castellanos-Gomez, A.; Arramel; Wojtaszek, M.; Smit, R.H.M.; Tombros, N.; Agraï, N.; Van Wees, B.J. Rubio-Bollinger, G. Electronic inhomogeneities in graphene: the role of the substrate 
interaction and chemical doping. Boletin Grupo Español Carbón, 2012, 25, 18-22.

[54] Castellanos-Gomez, A.; Smit, R.H.M.; Agraï, N.; Rubio-Bollinger, G. Spatially resolved electronic inhomogeneities of graphene due to subsurface charges. Carbon, 2012, 50 (3), 932-938.

[55] Bocquet, F.C.; Bisson, R.; Themlin, J.-M.; Layet, J.-M.; Angot, T. Reversible hydrogenation of deuterium-intercalated quasi-freestanding graphene on $\mathrm{SiC}(0001)$. Phys. Rev. B - Condens. Matter. Mater. Phys., 2012, 85 (20), article \# 201401.

[56] Luo, Z.; Yu, T.; Kim, K.-J.; Ni, Z.; You, Y.; Lim, S.; Shen, Z.; Wang, S.; Lin, J. Thickness-dependent reversible hydrogenation of graphene layers. ACS Nano, 2009, 3 (7), 1781-1788.

[57] Hornekaer, L.; Šljivančanin, Ž.; Xu, W.; Otero, R.; Rauls, E.; Stensgaard, I.; Lægsgaard, E.; Hammer, B.; Besenbacher, F. Metastable structures and recombination pathways for atomic hydrogen on the graphite (0001) surface. Phys. Rev. Lett., 2006, 96, article \# 156104.

[58] Balog, R.; Jørgensen, B.; Wells, J.; Lægsgaard, E.; Hofmann, P.; Besenbacher, F.; Hornekær, L. Atomic hydrogen adsorbate structures on graphene. J. Am. Chem. Soc., 2009, 131 (25), 87448745.

[59] Waqar, Z.; Klusek, Z.; Denisov, E.; Kompaniets, T.; Makarenko, I.; Titkov, A.; Saleem, A. Effect of atomic hydrogen sorption and desorption on topography and electronic properties of pyrolytic graphite. Electrochem. Soc. Proceed., 2000, 16, 254-265.

[60] Trunin, R.F.; Urlin, V.D.; Medvedev, A.B. Dynamic compression of hydrogen isotopes at megabar pressures. Phys. Usp., 2010, 53, 605-622.

[61] Gupta, B.K.; Tiwari, R.S.; Srivastava, O.N. Studies on synthesis and hydrogenation behavior of graphitic nanofibers prepared through palladium catalyst assisted thermal cracking of acetylene. J. Alloys Compd., 2004, 381, 301-308.

[62] Park, C.; Anderson, P.E.; Chambers, A.; Tan, C.D.; Hidalgo, R.; Rodriguez, N.M. Further studies of the interaction of hydrogen with graphite nanofibers. J. Phys. Chem. B, 1999, 103, 1057210581.

[63] Lin, Y.; Ding, F.; Yakobson, B.I. Hydrogen storage by spillver on graphene as a phase nucleation process. Phys. Rev. B - Condens. Matter. Mater. Phys., 2008, 78, article \# 041402.

[64] Singh, A.K.; Ribas, M.A.; Yakobson, B.I. H-spillover through the catalist saturation: An AB initio thermodynamics study. ACS Nano, 2009, 3, 1657-1662.
[65] Wang, L.; Yang, R.T. New sorbents for hydrogen storage by hydrohen spillover - A review. Ener. Environ . Sci., 2008, 1, 268279.

[66] Wang, L.; Yang, R.T. Hydrogen storage on carbon-based adsorbents and storage at ambient temperature by hydrogen spllover. Catal Rev - Sci. Eng., 2010, 52, 411-461.

[67] Gao, Y.; Zhao, N.; Li, J.; Liu, E.; He, C.; Shi, C. Hydrogen spillover storage on Ca-decorated graphene. Int. J. Hydro Ener., 2012, 37 (16), 11835-11841.

[68] Wang, L.; Yang, R.T. Molecular hydrogen and spiltover hydrogen storage on high surface area carbon sorbents. Carbon, 2012, 50 (9), 3134-3140.

[69] Han, S.S.; Jung, H.; Jung, D.H.; Choi, S.-H.; Park, N. Stability of hydrogenation states of graphene and conditions for hydrogen spillover. Phys. Rev. B - Condens. Matter. Mater. Phys., 2012, 85 (15), article \# 155408.

[70] Zuettel, A. In Materials of Int. Hydrogen Research Showcase 2011, University of Birmingham, UK, April 13-15, 2011; http://www.ukshec.org.uk/uk-shec/showcase/ShowcasePresentations.html (accested May 15, 2011).

[71] Fruchart, D. In Materials of Int. Hydrogen Research Showcase 2011, University of Birmingham, UK, April 13-15, 2011; http://www.uk-shec.org.uk/uk-

shec/showcase/ShowcasePresentations.html (accested May 15, 2011).

[72] Akuba, E. In Materials of Int. Hydrogen Research Showcase 2011, University of Birmingham, UK, April 13-15, 2011; http://www.ukshec.org.uk/uk-shec/showcase/ShowcasePresentations.html (accested May 15, 2011).

[73] Kim, J.W. In Materials of Int. Hydrogen Research Showcase 2011, University of Birmingham, UK, April 13-15, 2011; http://www.ukshec.org.uk/uk-shec/showcase/ShowcasePresentations.html (accested May 15, 2011).

[74] Satyapal, S.; Petrovic, J.; Read, C.; Thomas, G.; Ordaz, G. The U.S. Department of Energy's national hydrogen storage project: progress towards meeting hydrogen-powered vehicle requirements. // Catal. Today, 2007, 120, 246-257. (www.eere.energy.gov/hydrogenandfuelcells).

[75] DOE targets for onboard hydrogen storage systems for light-duty vehicles, 2012. http://wwwl.eere.energy.gov/hydrogenandfuelcells/storage/pdfs/targets_onboard_hydro_storage.pdf. (accested May 20, 2012). 